\title{
EL MONUMENTO COMO TESTIMONIO: ESTUDIO HISTÓRICO-CONSTRUCTIVO DE LA ERMITA DE SANTA MARGARITA DE ABEJUELA (TERUEL, ESPAÑA] Y PROPUESTAS DE INTERVENCIÓN
}

\author{
THE MONUMENT AS A TESTIMONY: HISTORICAL AND CONSTRUCTIVE RESEARCH OF THE \\ HERMITAGE OF SAINT MARGARET OF ABEJUELA (TERUEL, SPAIN] AND PROPOSALS FOR \\ INTERVENTION
}

DOMINGO SÁNCHEZ ZURIAGA

\begin{abstract}
RESUMEN
Alejada de la localidad de Abejuela, a la que actualmente pertenece, y emplazada en las zonas altas de la sierra de Javalambre, la ermita de Santa Margarita es un edificio de reducidas dimensiones y pobre aspecto exterior. Sin embargo, el interior nos muestra un magnífico ejemplo de iglesia medieval de arcos diafragma y armadura de madera. La investigación llevada a cabo sobre el edificio durante los años 2006 y 2007 nos permitirá identificar su origen, localizar y datar sus diferentes fases, e incluso aventurar los promotores de sus etapas constructivas. La metodología aplicada, que va desde el levantamiento de planos hasta la investigación en archivos, pasando por análisis constructivos y químicos, nos permitirá avanzar no solo en el conocimiento del edificio, sino también en el de la población a la que sirvió de parroquia, y en el de toda la zona, antigua frontera entre reinos. Todas estas conclusiones resultarán de aplicación ante futuras intervenciones en el edificio y su entorno.
\end{abstract}

\section{PALABRAS CLAVE}

Ermita, arquitectura gótica, Teruel.

\begin{abstract}
Far from the village of Abejuela, which currently belongs to, and located in the highlands of the Javalambre sierra, the hermitage of Saint Margaret is a small sized and poor-appearance building. The interior, however, shows us a great example of medieval church with diaphragm arches and wooden frame. Research carried out on the building during the years 2006 and 2007 will allow us to identify its origin, locate and date different construction stages, and even venture their promoters. The methodology applied, ranging from surveying to archival research, including constructive and chemical analysis, will allow us to advance in knowledge not only of the building but also of the population it served as a parish, and also of the entire area, former border between realms. All these findings should be applicable to future interventions in the building and its surrounding area.
\end{abstract}

\section{KEY WORDS}

Hermitage, gothic architecture, Teruel. 
De Almansa nuestros antiguos / se bajaron a Abejuela / y lograron de tu escuela / favores muy repetidos.

Esta estrofa, cantada por los fieles en el interior del templo dedicado a Santa Margarita, en lo alto de la sierra de Javalambre, al sur de la provincia de Teruel, y repetida cada 20 de julio, nos sitúa en el origen de nuestra investigación, en el punto en el que la tradición oral, la devoción religiosa, el sentimiento de una comunidad, el entorno y el edificio se unen para formar un todo donde la historia de un pueblo y la arquitectura de un edificio se dan la mano.

La ermita de Santa Margarita se yergue sobre un pequeño otero en las altiplanicies de la zona sur de la sierra de Javalambre, alejada del núcleo urbano de Abejuela, a cuyo municipio pertenece en la actualidad. Es un edificio modesto, de reducidas dimensiones, y si no fuera por el encalado que actualmente lo recubre bien podría confundirse con otras edificaciones dispersas que podemos observar en su entorno, dedicadas a refugios para el ganado. Solo su posición en alto y algunos elementos constructivos en sillería indicarán al observador que la contemple por vez primera que se trata de otro tipo de edificio. Un estudio riguroso de sus características constructivas y de su historia, sin embargo, nos descubrirán el papel que tuvo este edificio en el asentamiento de la población en la zona, en el desarrollo de sus actividades, en sus épocas de bonanza y decadencia. Estas piedras nos trasladarán a épocas de conquista, de repoblación, de frontera, y finalmente de éxodo y abandono. El edificio nos planteará preguntas que solo la historia del entorno nos permitirá responder, y al contrario: las incógnitas que el estudio histórico de la zona nos genere se verán en muchos casos clarificadas por el mismo edificio.

El presente artículo se basa en la investigación realizada durante los años 2006 y 2007 por los arquitectos Domingo Sánchez Zuriaga y Enrique Vicente Cama Bonet, y presentada como Proyecto Final del Master de Restauración y Rehabilitación del Patrimonio [MRRP] de la Universidad de Alcalá de Henares.

\section{Análisis preliminar: el edificio y su entorno}

Los datos de partida de la investigación son dos: el edificio como una realidad tangible, construida, y el entorno que lo rodea, no solo a nivel geográfico, sino también social (Figura 1).

El edificio conforma un volumen rectangular con un pequeño entrante o quiebro en su lado oeste. La orientación longitudinal es E-O casi con exactitud. Los muros se construyen en mampostería con algunos (pocos) elementos apreciables de sillería. Los vanos son escasos y de reducidas dimensiones; la fachada sur es la que contiene los dos accesos: uno, realizado en arco de medio punto de sillería y precedido de un porche, que se corresponde con el acceso al templo, y otro situado más al este, mucho más tosco, que da acceso a unas estancias anexas. La cubierta es de teja árabe a dos aguas, resultando el faldón sur mucho más desarrollado (incluso generando cierta desproporción) que el norte. Destaca sobre ella un pequeño tramo sobreelevado (Figura 2).

El acceso al interior se realiza por la puerta realizada en arco de medio punto de sillería situada en la fachada sur. Previamente se atraviesa un porche de dimensiones generosas en comparación con las del edificio, abierto al sur pero protegido en parte por un murete. Este porche tiene unas proporciones rectangulares, pero, como ocurría al describir la volumetría del edificio, también aquí aparece un pequeño recodo o entrante en uno de los extremos. Un banco bajo se adosa a sus muros, interrumpiéndose en la puerta de acceso al templo, situada en el muro norte del porche (que en realidad es el muro sur de la nave del templo), y junto a la que hay una pequeña ventana alta. En la parte superior de este muro encontramos dos canes o ménsulas de piedra toscamente labrada, rematados en medio bocel (Figura 3).

En este breve recorrido exterior, y sin profundizar más en el análisis, ya se pueden localizar algunos elementos que nos pueden dar idea de que el edificio no se construyó en una sola fase, sino que ha sido objeto de adiciones sucesivas: el quiebro en la volumetría en su testero este, la desproporción de los dos faldones de cubierta, el tramo sobreelevado de la misma, el recodo existente en el porche, los canes o ménsulas de piedra aparentemente sin uso, etc.

Ya en el interior, sorprende la monumentalidad del espacio, conseguida al tratarse de un espacio único, 

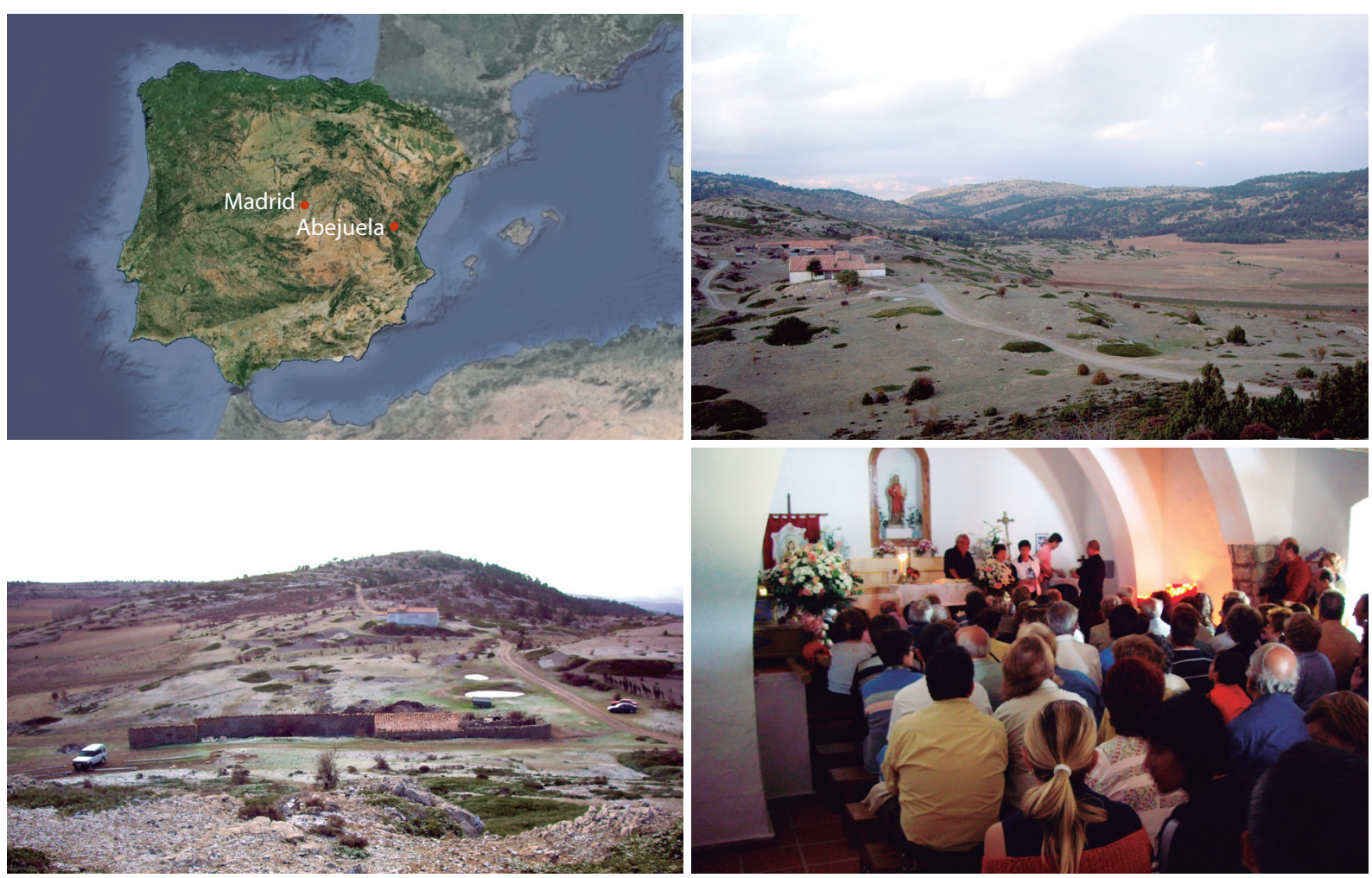

De izquierda a derecha y de arriba a abajo:

Figura 1

Ubicación de Abejuela respecto a Madrid. Entorno geográfico: la ermita de Santa Margarita y la Hoya de Almansa. Entorno social: fieles congregados en la ermita el día de la fiesta de Santa Margarita, 20 de julio.

Fuente: Google Earth (c)2013 y fotografías del autor.

Figura 2

Vista general de la ermita desde el noreste y desde el suroeste.
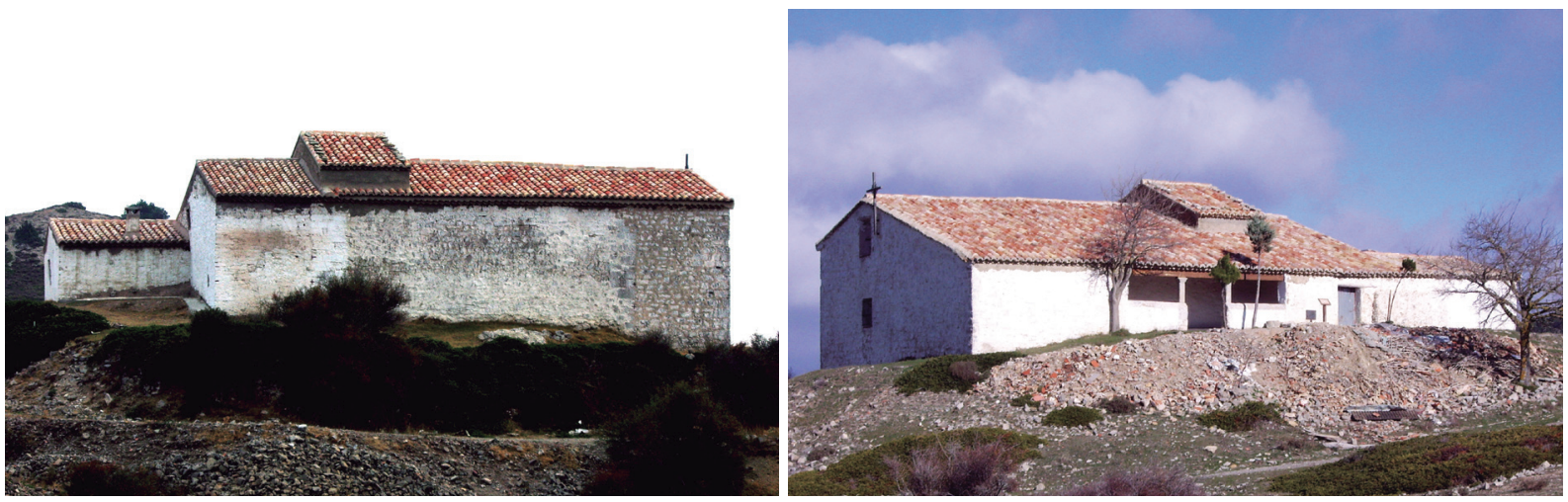
una "iglesia-salón" de nave única. Sorprende también la presencia de arcos diafragma ${ }^{2}$ (en número de tres) para soportar la cubierta (ya que los muros no presentan contrafuertes ni refuerzos de sillería en las zonas de muro coincidentes con ellos), así como el grosor de los mismos; también llama la atención los apenas 2 metros que existen en cada tramo entre arco y arco. El acceso se sitúa en el tercer tramo desde el presbiterio. El altar se sitúa al este, adosado al muro de cierre del presbiterio ${ }^{3}$, y, junto al mismo se ubican unos escalones y una tosca abertura que da paso a una pequeña sacristía. Al oeste, a los pies de la nave, y a unos 2 metros del último arco diafragma, se ubica un coro alto soportado por un pilarcillo central. Bajo el coro se encuentra el acceso a un espacio anexo, de doble altura, que se corresponde con el quiebro ob-

1. No confundir con las hallenkirche góticas alemanas, también conocidas en España como "templos columnarios", que son templos de planta rectangular de más de una nave (tres o incluso cinco) que presentan la particularidad de tener todas ellas la misma altura, generando un espacio interior homogéneo sustentado por pilares (Muñoz , 1996).

2. Según Zaragozá (1990), se puede definir estos arcos como "una serie de arcos, dispuestos transversalmente al eje longitudinal de la nave que se pretende cubrir, que tienen la función de soportar la cubierta del edificio" (p.10).

3. En posición anterior, por tanto, a las disposiciones del Concilio Vaticano II, que establecía que el celebrante tenía que estar de cara a los fieles, con lo que el altar debe permitir situarse tras él. servado en el porche. El tramo del coro resulta considerablemente mayor que los situados entre arcos diafragma (casi 4 metros de longitud) (Figura 4a).

La cubierta es de madera, con tres vigas principales que acometen de arco a arco, y un conjunto de pequeñas vigas o pares que se apoyan sobre las anteriores y sobre los muros norte y sur. Sobre el presbiterio no se observa la armadura de madera, sino tres bóvedas aproximadamente vaídas, de factura poco cuidada, resultando la central más ancha que las laterales. La ubicación de estas bóvedas se corresponde con la sobreelevación de la cubierta apreciable desde el exterior. Los acabados interiores se resuelven con un enlucido en todos los paramentos verticales, en el que tras sucesivas capas de encalado se puede observar un despiece en sillares fingidos. El pavimento actual es un solado de baldosa de gres rústico; no obstante, aún se pueden observar restos de un solado anterior, realizado a base de baldosas cuadradas de barro colocadas con las juntas contrapeadas. El espacio se ilumina mediante dos huecos practicados en el testero oeste del templo (el superior de los cuales presenta unos soportes laterales para alojar la pequeña campana o campanico ${ }^{4}$ que se actualmente se coloca solo el día 20 de julio), y a través de la pequeña ven-

4. El tipo de esta campana es el de "campana de señales" (Llop, 1996); la masculinización del elemento y el diminutivo -ico son frecuentes en el habla popular aragonesa.
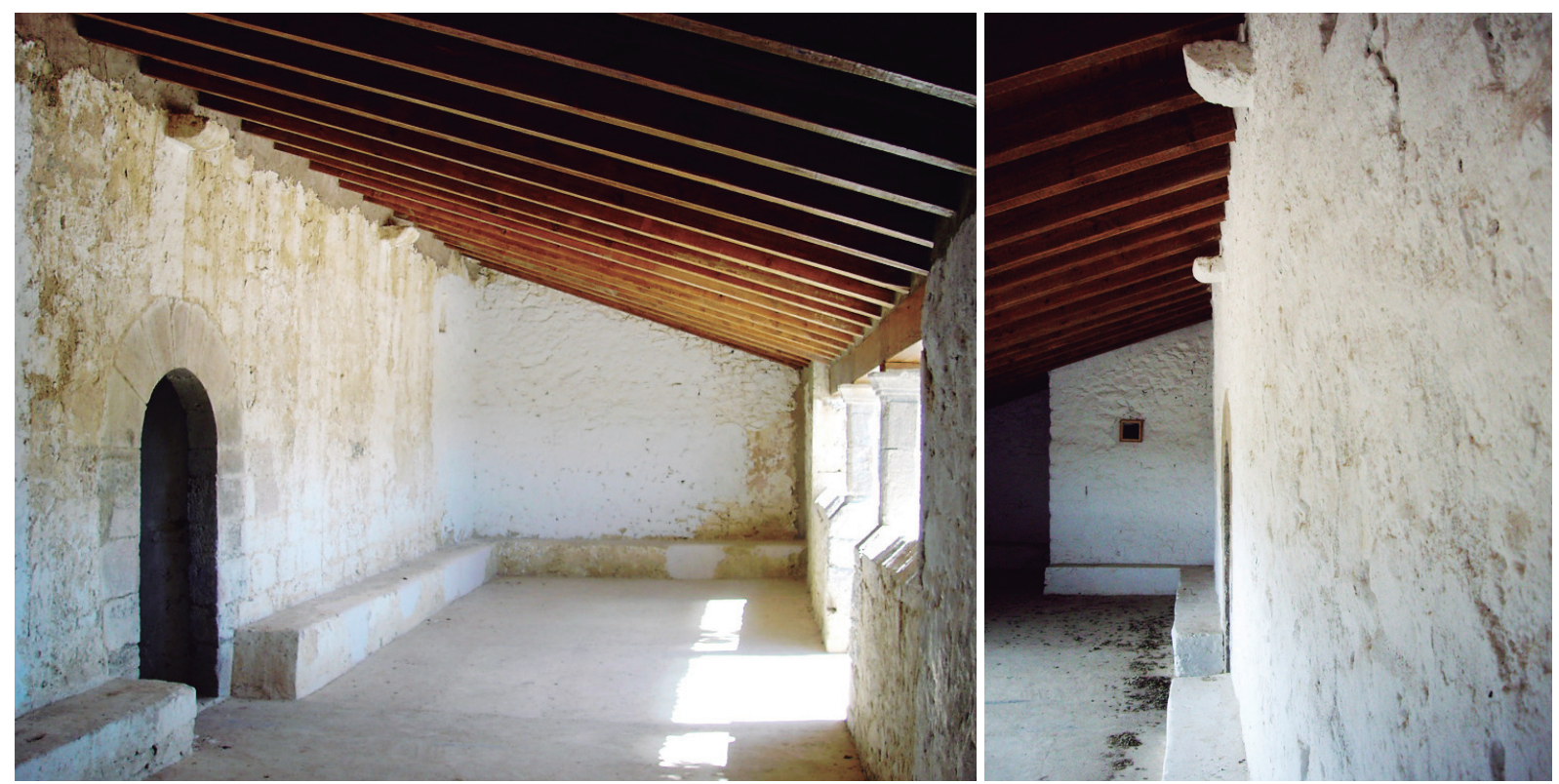


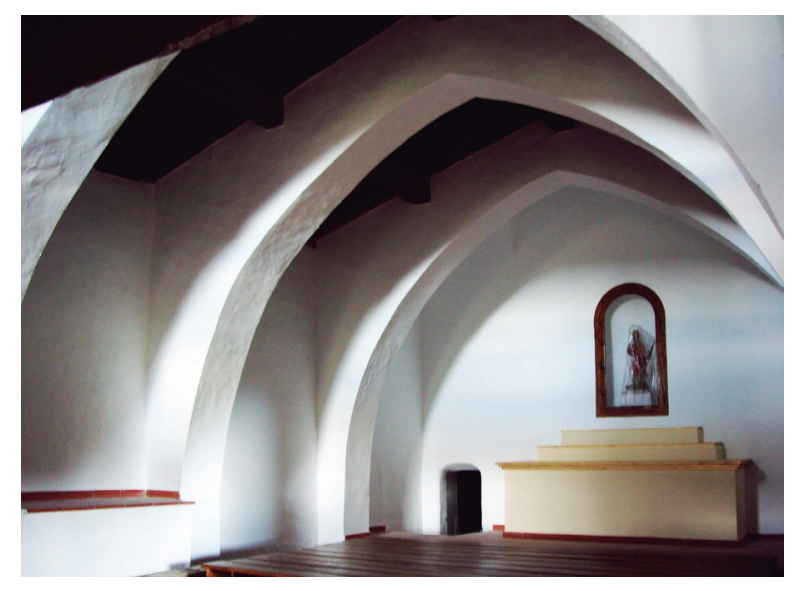

De izquierda a derecha y de arriba a abajo:

Figura 3 (página anterior)

Vistas generales del porche.

Figura 4 (arriba)

Vista del interior del templo hacia el este, con el presbiterio al fondo, $y$ hacia el oeste, con el coro alto a los pies.

Figura 5

Estancias anexas ("casa de los caridaderos").

tana practicada en el muro sur de la nave, en la zona del presbiterio, recayente al porche. La sacristía tiene una pequeña aspillera orientada hacia el este.

De nuevo aparecen a primera vista ciertos indicios de que la construcción del templo no fue un acto único, sino una sucesión de fases: se percibe claramente el tramo del coro como un elemento distinto de la zona de arcos diafragma, del mismo modo que las bóvedas situadas sobre el presbiterio; los huecos de acceso a la pequeña sacristía y el anexo bajo la escalera del coro son más bien perforaciones en los muros, posteriores a la ejecución de los mismos; el solado actual, situado a un nivel más alto que el porche, se ubica claramente sobre una capa anterior, visible en la zona de la puerta. No obstante, resulta clara la intención de unificar todo el conjunto mediante la aplicación del enlucido a todas las superficies, que junto con el carácter unitario del espacio en sí, confieren al interior una considerable homogeneidad.
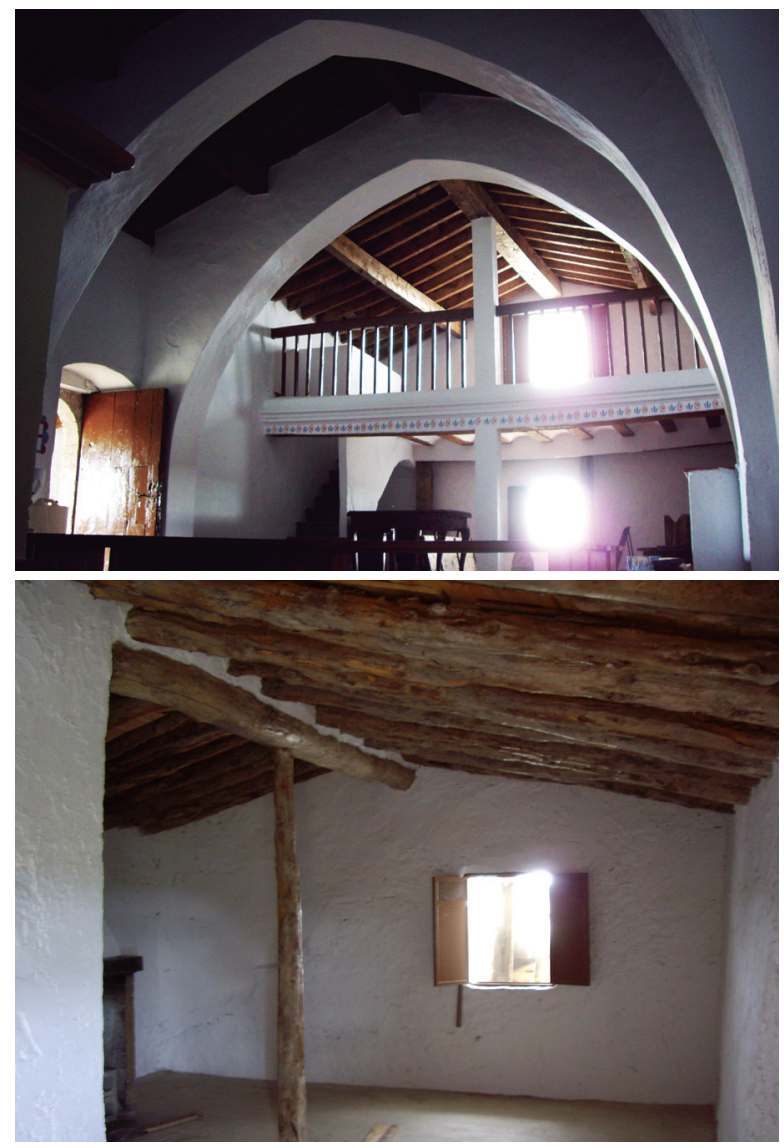

La otra puerta existente en la fachada sur carece de porche previo. Es el acceso a unas estancias anexas (conocidas como "casa de los caridaderos"5), adosadas al muro de cierre del presbiterio. El interior de las mismas es en extremo pobre, sin enlucidos en las paredes y con la cubierta de madera a dos aguas formada por rollizos de mucha menor calidad que las maderas escuadradas del interior del templo. El espacio interior se divide en dos estancias: una de planta alargada que se adosa directamente al testero este del templo, ocupando toda la anchura del mismo y del porche, y que en su extremo norte presenta un altillo al que se accede por una escalera; y un espacio adosado, que es el que en la planta general del edificio conforma el quiebro en el extremo sureste, de planta aproximadamente cuadrada.

5. "Caridadero" es un cargo voluntario y anual, que solicitan las familias de Abejuela, encargándose de repartir gratuitamente pan y vino (la "caridad") al finalizar la misa de la Santa en la ermita el 20 de Julio. 
En cuanto al entorno que rodea el edificio, nos encontramos a 4 kilómetros de Abejuela, el pueblo más cercano, en lo alto de la sierra. Sorprende por la altitud (1,500-1,700 metros) y lo agreste del paisaje encontrar amplias zonas cultivadas en el fondo de algunos valles, como la llamada Hoya de Almansa que se ubica a los pies de la ermita: son lo que en la zona se conoce como navas, y que, más que valles, son formaciones geológicas que reciben el nombre científico de Poljes, cubetas endorreicas provocadas por los fenómenos de disolución kárstica que se producen en la zona: los finos y limos provocados por la erosión se acumulan en el fondo de la cubeta, junto con las aguas recogidas y filtradas en él, generando tierras fértiles (Figura 6). Resulta ciertamente llamativa una característica del edificio relacionada con la evacuación de las aguas de la zona: la tradición popular señala que las aguas que caen por el faldón norte de la ermita van a dar al río Mijares, que llega al mar en Castellón; mientras que las que caen por el faldón sur van a dar al río Turia, que desemboca en Valencia, más de 60 kilómetros al sur. Más allá de lo curioso del dato, resulta muy significativo en cuanto a la situación exacta de la ermita y la configuración geográfica de toda la zona de las navas.

La nava situada justo debajo de la ermita se conoce como la Hoya ${ }^{6}$ de Almansa, y en las inmediaciones localizamos otras navas: la Nava de Torrijas (la más singular por sus dimensiones, de más de 6 kilómetros de longitud), la Nava del Puerco, la Nava del Caballo y la Nava del Azor ${ }^{7}$ (Figura 7). En todas ellas, y también en la Hoya de Almansa, se cumplen más o menos los mismos elementos: un fondo por donde a veces corre un reguero y existen fuentes o depósitos de agua, una zona central formada por pastizales, habitualmente sin cultivar, zonas laterales cultivadas hasta donde las laderas se elevan y comienzan a ser pedregosas, y edificaciones (masías) dispersas por el perímetro, a veces agrupadas en pequeños grupos

6. La denominación "Hoya" en vez de "Nava" aparece ya en documentos del siglo XVII; no obstante, se trata de un polje con las mismas características que el resto de las navas de la zona.

7. Nótese que las denominaciones, a excepción de las toponímicas, son relativas a animales domésticos, que hoy en día no podemos localizar entre la fauna salvaje de la zona, lo cual puede suponer un indicio del poblamiento de las mismas.

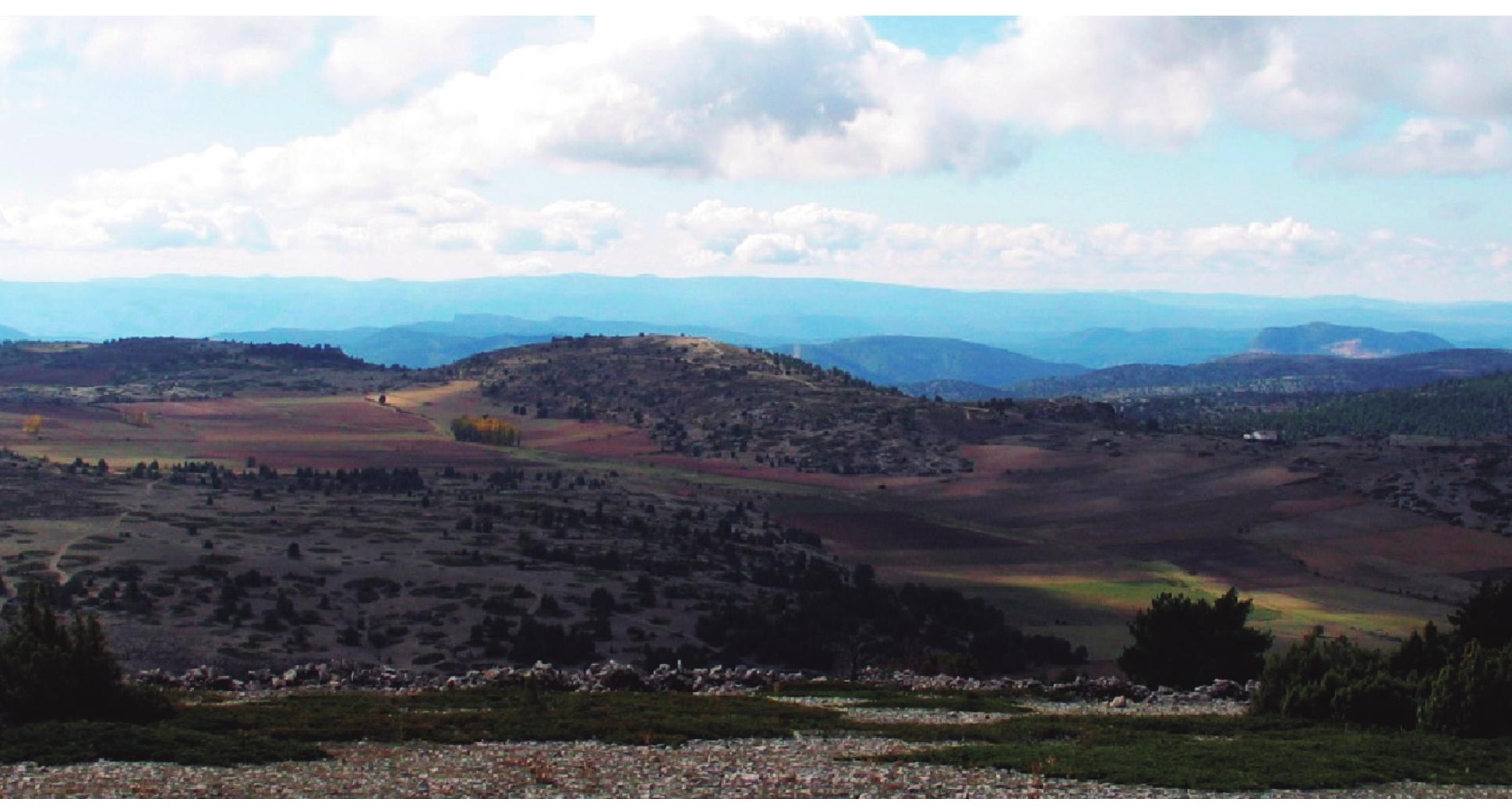


(masadas), que actualmente tienen un uso eminentemente ganadero, pero conservan trazas que nos remiten a un anterior uso residencial. En los casos de las Navas de Torrijas y de Almansa, además, aparece la figura de la ermita en posición central, más o menos equidistante de los núcleos de edificaciones que la rodean. Además de las construcciones que quedan en pie, alrededor de la ermita se aprecian multitud de muros y restos de construcciones, así como materiales de construcción (restos de tejas, ladrillos cocidos, cerámicas decoradas, etc), que fácilmente se pueden relacionar con un anterior poblamiento establecido en este punto, quizás la Almansa que da nombre a toda la zona.

\section{Análisis constructivo del edificio: algunas res- puestas y nuevas preguntas}

Tras esta observación general del edificio y su entorno, corresponde ahora analizar más a fondo la fábrica del mismo. Este análisis se realizó en varias fases: en primer lugar, una observación detallada del edificio y de todos sus elementos; posteriormente se realizó un levantamiento planimétrico exahustivo (incluyendo
De izquierda a derecha y de arriba a abajo:

Figura 6 (página anterior)

La Hoya de Almansa desde el noreste, con la ermita al fondo.

Figura 7

Navas de Torrijas, del Puerco, del Caballo y del Azor.
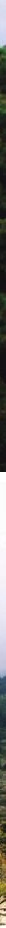


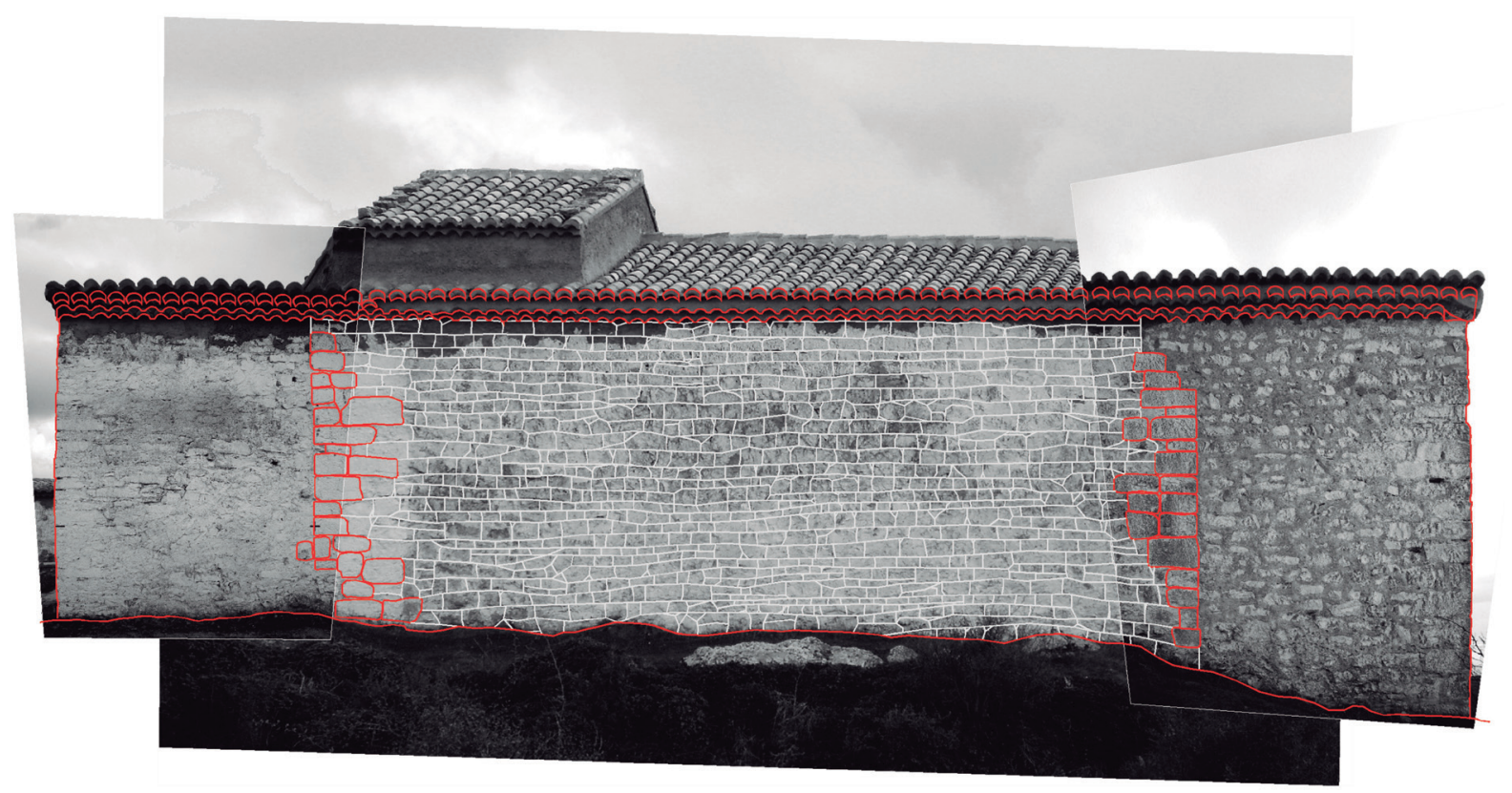

técnicas de fotogrametría ${ }^{8}$ en el levantamiento de sus alzados) (Figura 8), y finalmente se analizó la composición química de las piezas básicas que conforman su fábrica: piedra y morteros de junta.

Observación y levantamiento de planos: muchas de las incógnitas que se planteaban en la observación preliminar quedaron clarificadas al realizar el levantamiento de planos (Figura 9a). El muro norte es quizás el que mejor muestra toda la diacronía del edificio. Embutidas en el mismo se encuentran dos líneas de sillares que destacan del resto, ejecutado en mampostería. Son claramente dos antiguas llaves de esquina, y se puede comprobar en la planta como se corresponden con la posición de los antiguos testeros del templo, uno de los cuales (el testero este, sobre el que se apoya el altar) se conserva en la actualidad como separación nave-habitaciones anexas ("casa de los caridaderos"), mientras que el otro ha desaparecido para permitir la adición del cuerpo del coro. Se verifica así que la zona de arcos diafragma (a la que llamaremos en adelante "iglesia-1") es la más antigua conservada del edificio, a la que se añadieron

8. Para la restitución fotogramétrica se utilizó el programa RolleiMetric MSR, de Rollei. en su extremo oeste el tramo del coro (demoliendo la original fachada oeste) y en el este el anexo de la casa de los caridaderos. Se observa también en los planos la potencia de los muros de la nave (de entre 90 centímetros y 1 metro de espesor), que justifica el hecho de que no existan contrafuertes para contrarrestar el empuje de los arcos diafragma, y se puede comparar el grosor de esos muros con los de otros elementos como los cierres del tramo del coro o las habitaciones anexas del este, que oscilan entre los 50 y 60 centímetros, a pesar de encontrarse enrasados con los de la nave por su cara exterior. Los muros del anexo de planta cuadrada a las habitaciones del testero este presentan mucha peor factura que el resto; se puede observar cómo no existe traba entre ellos y el resto de la zona anexa, con lo que este elemento (que además es el que produce el quiebro en planta) se puede considerar cómo un espacio adosado a la misma, de factura posterior. El quiebro que se producía en el interior del porche se corresponde con un espacio anexo a la nave al que se accede por el bajo coro. En la perforación en el muro que hace las veces de puerta se puede observar la total falta de traba entre los cierres de ese anexo (que además son de muy mala factura) y los muros de nave y porche, con lo que puede concluirse que se trata de un espacio aña- 


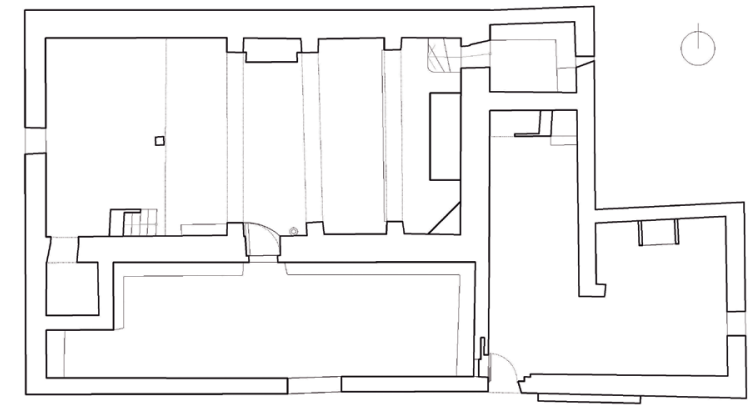

a

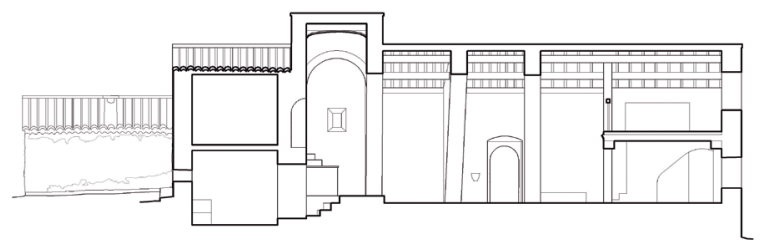

C

dido, posterior a la construcción del tramo del coro y del porche. Se observa que dicho anexo tiene doble altura, con mechinales a media altura, y un acceso cegado al coro alto; no obstante, hasta este punto se sigue sin poder establecer cuál era su función. Los canes de piedra labrada existentes en el muro norte del porche, sobre el acceso a la nave del templo, que actualmente presentan una posición descentrada con respecto al conjunto del porche, dividen, sin embargo, en tres tramos aproximadamente iguales el muro sur original de la iglesia-1, según podemos observar en el plano de planta. Su función era, con toda seguridad, soportar una viga adosada al muro de cierre de la nave por su cara exterior, sobre la que se apoyaran las vigas que conformarían un porche protegiendo el acceso. Podemos concluir así que la iglesia-1 originalmente contaba con un porche orientado al sur, pero no con las dimensiones actuales ni con las viguetas acometiendo directamente al muro como ocurre hoy día. En la casa de los caridaderos también encontramos algunos elementos de sillería que nos remiten a llaves de esquina: una de ellas, que recorre el muro de cierre del presbiterio en toda su altura, se corresponde con la esquina sureste original de la iglesia-1, y nos permite observar cómo se continuó el testero para configurar el porche y separarlo de este

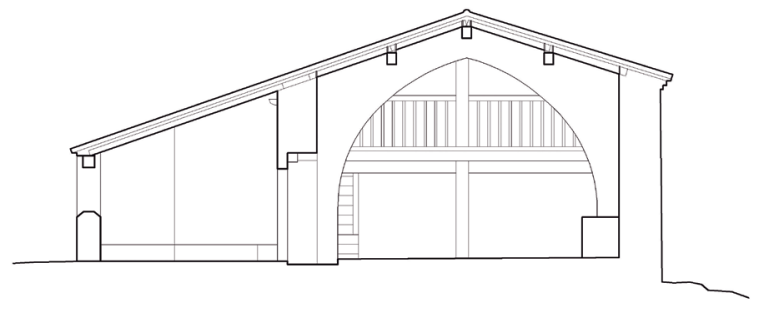

b

De izquierda a derecha y de arriba a abajo:

Figura 8 (página anterior)

Fotogrametría de la fachada norte.

Figura 9

(a) Planta del edificio según el levantamiento efectuado. (b) Sección transversal del edificio según el levantamiento efectuado.

(c) Sección longitudinal del edificio según el levantamiento efectuado.

anexo. Otras llaves de sillería presentes en el interior de la casa de los caridaderos, en este caso más bien de sillarejo de menor calidad, parecen definir una puerta de acceso situada en la fachada este; esta puerta aparece hoy en día tapiada con mampuesto, y a este tapiado acomete el muro de cierre de la pieza anexa de planta cuadrada, corroborando que se trata de un añadido posterior. Este primer espacio anexo debió tener una planta alzada, hoy desaparecida, a juzgar por la ventana alta existente en su muro este y por los restos que indican la continuidad de la pequeña escalera que sube al altillo situado al fondo de la estancia (dispuesto para dejar sitio bajo él a la sacristía anexa a la nave, la cual, por tanto, se reconoce también como posterior a la iglesia-1 y coetánea a esta primera zona de la casa de los caridaderos).

Nos quedará analizar con detenimiento los alzados oeste y sur (ya que ya hemos hablado del norte) para ver si el levantamiento gráfico nos da alguna clave más para la comprensión del edificio. El alzado sur se configura principalmente por el murete de cierre del porche, rematado por piezas de piedra labrada con las esquinas rebajadas, y que deja un acceso flanqueado por dos columnillas con sencillos capiteles, también en piedra. Sorprende en este muro la diferencia de 
material (piedra caliza de color pardo-amarillento) y calidad de labra en las piezas con las esquinas rebajadas colocadas como remate del muerte, y el resto de elementos de piedra de este mismo murete (piedra caliza de color gris oscuro). La primera resulta significativamente parecida al tipo de piedra que podemos encontrar en la sillería de la puerta de acceso a la nave, o en los arcos del interior. Su forma, con sección de medio octógono, permitiría aventurar la hipótesis de que se tratara de elementos reutilizados del porche original de la iglesia-1, en concreto quizás de unos hipotéticos pilares de sección octogonal, ha-

De izquierda a derecha y de arriba a abajo:

Figura 10

Diferentes tipos de piedra utilizados en elementos de cierre del porche. Pilares octogonales de piedra utilizados en construcciones similares de la época (Fuente Vieja en La Yesa, a 10 km de Abejuela). Porche de la ermita de Vera en Valencia.

Figura 11 (página siguiente)

Maquetas de la evolución desde la iglesia-1 a la iglesia-3. Elaboración propia.
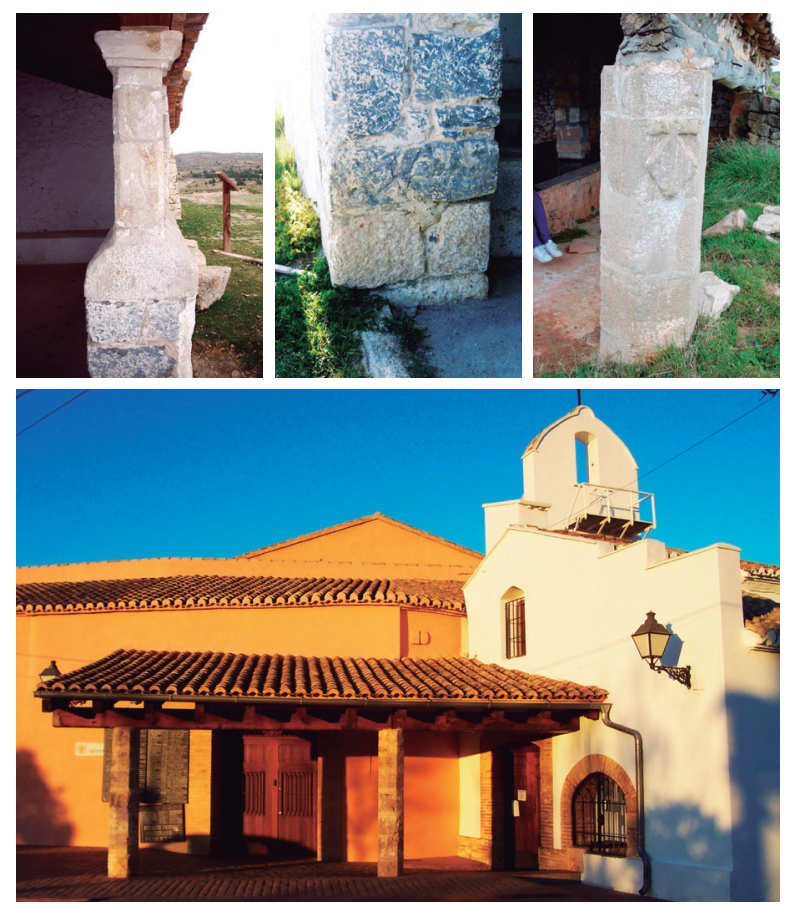

bituales en los porches de otras ermitas y edificios similares, incluso algunos presentes en la zona (Figura 10a). No obstante, esto no deja de ser una hipótesis, careciendo actualmente de datos que nos permitieran definir completamente el porche de la iglesia-1.

Por su parte, el alzado oeste es quizás el más homogéneo de todos los del edificio. No presenta esquinas ni cuerpos superpuestos, ni elementos de sillería que nos remitieran a adiciones sucesivas. Parece, por tanto, que se ejecutó de una sola vez. Sí llama la atención un único sillar de ciertas proporciones, en una extraña posición, prácticamente en la cumbrera, casi interrumpiendo el sencillo alero de teja; hasta este punto, poco más podemos decir de este elemento. Los huecos presentes en esta fachada no están alineados en vertical, y presentan signos de haber sido modificados: el superior, que aloja la campana, casi no deja espacio para disponer un dintel de tamaño suficiente bajo la viga central de la cubierta.

Hasta ahora, el levantamiento de planos y el contraste con una observación detallada de los elementos arquitectónicos y constructivos del edificio nos sitúa ante la hipótesis de una iglesia inicial (la iglesia-1) (Figura 11), de planta rectangular, conformada por la zona de arcos diafragma, con cabecera plana orientada hacia el este, y acceso lateral por la puerta existente (desconocemos si también existió un acceso a los pies de la nave, por haber desaparecido el testero oeste de la iglesia-1). Esta iglesia sería de nave única, sin espacios anexos ni añadidos, y tendría un porche previo al sur, cuyas viguetas se apoyarían sobre una gran viga soportada por los canes o ménsulas conservados, y quizás por pilares octogonales exentos en su extremo opuesto, cuyas piezas podrían haberse recolocado posteriormente en el murete del porche actual. A esta primera fase del edificio se le añaden, en una nueva etapa constructiva, un tramo de nave, más largo que los anteriores, situado a los pies, que conforma un coro alto, y unas bóvedas en la zona del presbiterio (para lo cual hay que sobreelevar la cubierta en ese tramo); se produce en esta fase también la remodelación del porche generando el murete y columnillas actuales (quizás reutilizando parte de elementos anteriores). El resultado (la que llamaremos "iglesia-2") vuelve a ser un volumen compacto, de planta rectangular sin quiebros ni elementos añadidos, más allá de la sobreelevación de las cubiertas sobre el presbiterio. En una fase posterior, se añade a este volumen la primera estancia de la casa de los caridaderos, con su acceso central, que justifica su 
alargada proporción rectangular por una cierta voluntad de mantener la homogeneidad del volumen global, sin generar quiebros en planta; la pequeña sacristía situada junto al altar, y bajo el altillo de esta estancia, correspondería también a esta fase, a la que llamaremos "iglesia-3". Es a este volumen al que en fases posteriores (desconocemos si coetáneas entre sí o no) se añadirán dos nuevos elementos, ejecutados claramente con peor factura y sin el cuidado por el acabado homogéneo del conjunto que observamos en fases anteriores: el pequeño cuerpo situado al oeste del porche, con acceso actual desde el bajo coro, y la estancia cuadrada anexa por el este, que rompe las proporciones rectangulares de la planta.

Análisis químicos9: el objetivo de la realización de análisis químicos, que nos aportarán datos sobre la composición mineralógica de los principales materiales que forman las fábricas del edificio (piedra y morteros de junta), es respaldar o desmentir las hipótesis formuladas en la fase anterior de observación y levantamiento planimétrico. El proceso realizado es el siguiente:

Muestreo: se decide la ubicación de las muestras a analizar según los elementos constructivos detectados en el análisis constructivo previo, y procurando representar todas las fábricas del edificio. Las muestras se tomaron con cincel, descartando las porciones externas para analizar únicamente material no alterado por agentes externos. Las muestras se localizaron y nombraron según la Figura 12.

Análisis: se utilizó para el análisis la técnica de la difracción de Rayos-X, incluida dentro de los métodos de investigación habituales para la caracterización mineralógica de estos materiales (Middendorf, 2005). Se empleó un difractómetro Seifert XRD 3003 TT, con geometría Bragg-Brentano. Las condiciones de trabajo del tubo de $\mathrm{Cu}$ fueron $40 \mathrm{kV}$ y $40 \mathrm{~mA}$, y la configuración del equipo incluía filtro de $\mathrm{Ni}$, rendija primaria de $0.3 \mathrm{~mm}$, secundaria de $0.3 \mathrm{~mm}$, rendija de detector de $0.2 \mathrm{~mm}$ y detector de centelleo.

Los registros se realizaron entre 5 y $65^{\circ} 2 \theta$, con un paso de $0.05^{\circ} 2 \theta$ y un tiempo de acumulación de $3 \mathrm{~s}$.

9. Los análisis químicos se realizaron en las instalaciones del Instituto de Ciencia de los Materiales de la Universidad de Valencia (ICMUV); agradecemos especialmente a Pablo Rafael Pardo Ibáñez la ejecución de los mismos y la interpretación de los resultados obtenidos, junto con los profesores Bastida, Roldán e lbáñez.
Tratamiento de datos. Identificación de fases cristalinas y análisis semicuantitativo: para la identificación de fases en las muestras estudiadas, realizada sobre los difractogramas de polvo desorientado de muestra total, se emplearon los programas EVA-PLUS y SEARCH, incluido en el sistema DIFFRACT-PLUS. En las estimaciones semicuantitativas se ha aplicado el método de las intensidades de referencia (Davis, 1989; Hubbard, 1988).

Gracias al análisis podemos establecer la proporción relativa de componentes de los morteros analizados.
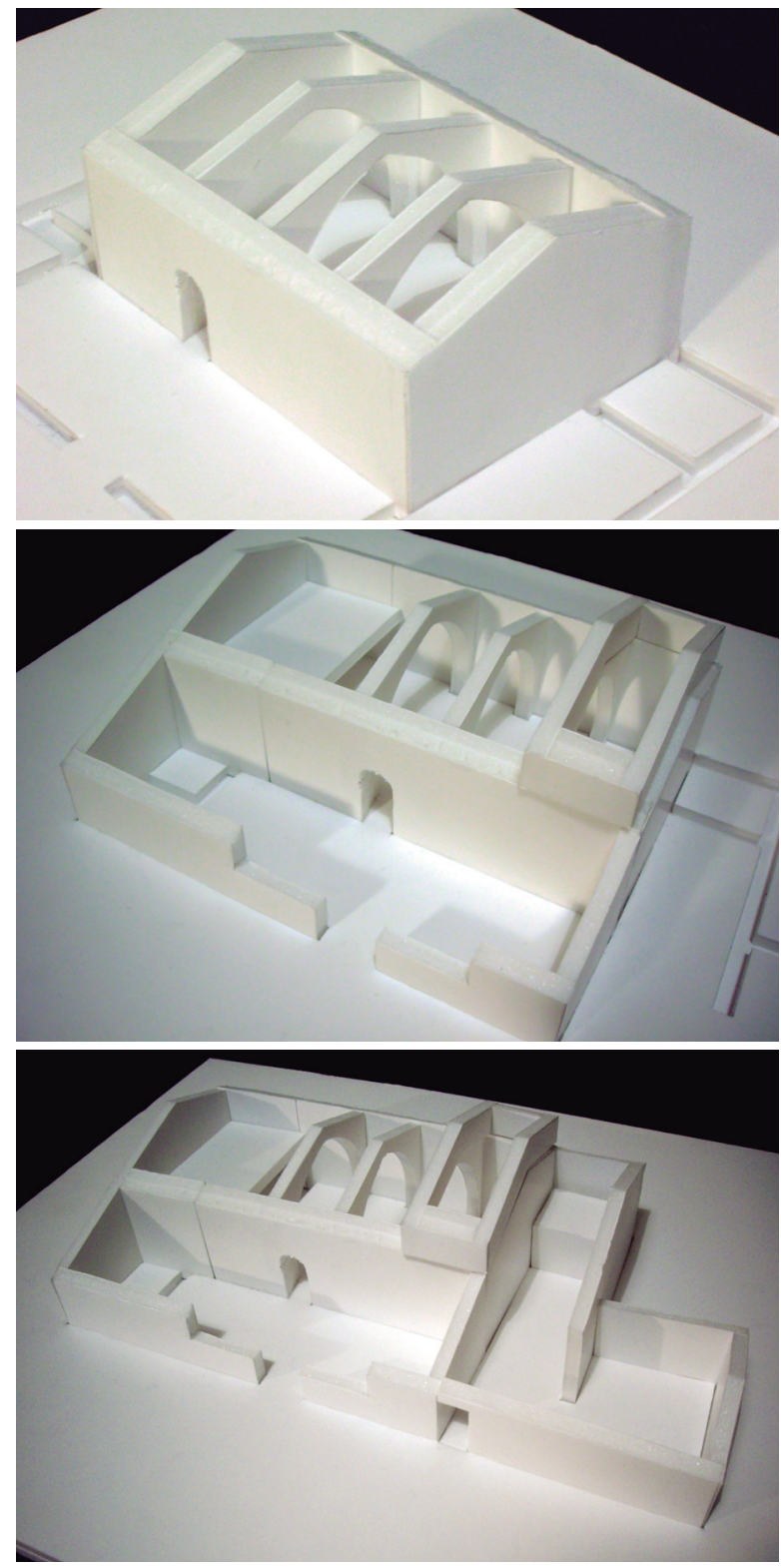


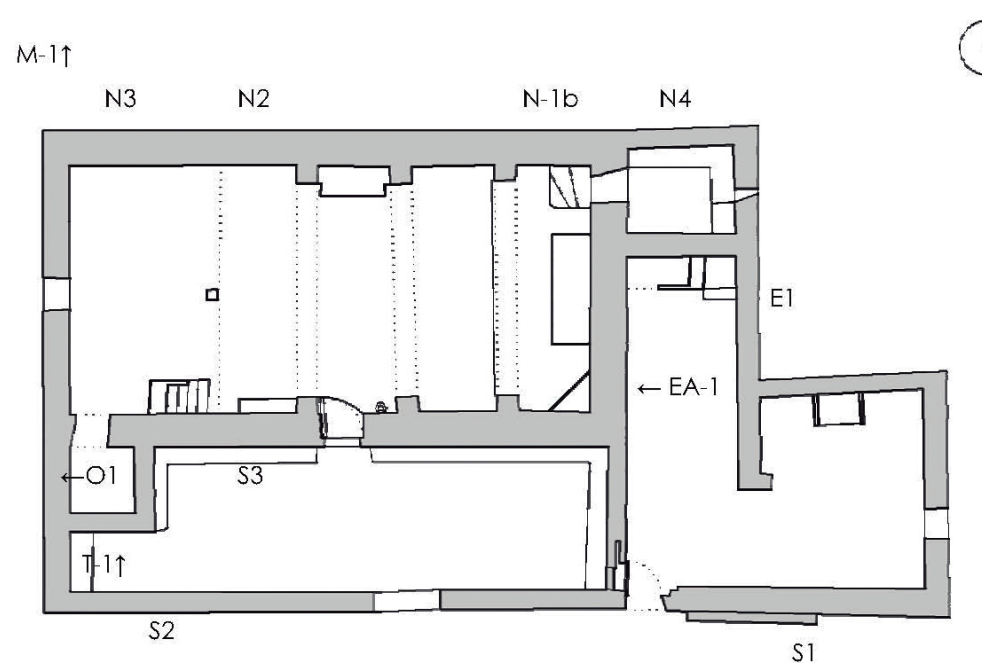

Principalmente nos interesa la proporción relativa de cal (carbonato cálcico en forma de calcita) y yeso de los mismos, puesto que según algunos autores (Gárate, 2002 y C. Aymat, comunicación personal, diciembre de 2006) de esta relación se puede deducir el origen árabe (o más bien la tradición constructiva árabe) de los mismos: porcentajes del $80-90 \%$ de cal en morteros con presencia de yeso, podrían calificarse de árabes o de tradición árabe. El origen árabe del edificio no se plantea como hipótesis, aunque sí el del asentamiento, cuyo topónimo Almansa tiene claro origen árabe, como se verá más adelante. Es, por tanto, una posibilidad que las fases más antiguas del edificio se realizaran en épocas cercanas a la conquista cristiana de la zona a los árabes, y que, por ello, se utilizaran técnicas constructivas o incluso mano de obra de esa procedencia. Rastros constructivos árabes en las fábricas nos podrían estar identificando las partes más antiguas del edificio.

Los resultados obtenidos, reflejados en la Tabla 1, nos permiten localizar morteros de tradición árabe en la zona occidental del muro norte, el testero oeste y el cierre sur del porche; en líneas generales, se corresponden con la denominada iglesia-2 (que a su vez engloba a la iglesia-1), mientras que los anexos situados al este presentan morteros posteriores. Los datos obtenidos por el análisis químico y las conclusiones extraídas del levantamiento coinciden en líneas generales.

También se realizaron análisis por difracción de Rayos-X de dos muestras de piedra, obtenidas de un sillar ubicado en el arco diafragma central, junto a la puerta, parte de cuyo revoco fue picado hace años para la realización de una cata (Figura 13). Se obtuvo una muestra más superficial (de color grisáceo), y otra más profunda (de color pardo-amarillento), del mismo sillar, gracias a presentar este una zona fracturada. Sorprende a primera vista el estado superficial de los sillares actualmente observables: la superficie es en extremo rugosa y fácilmente desescamable, apareciendo totalmente cristalizada. Los sillares del arco de entrada también están formados en su totalidad por cristales perceptibles a simple vista, aunque su superficie no es rugosa ni se desescama en absoluto. El análisis de las dos muestras obtenidas (Figura 14) dio como resultado que en ambos casos se trataba de calcita $\left(\mathrm{CaCO}_{3}\right)$, apareciendo en la muestra gris (la superficial) indicios de sulfatos, no presentes en la muestra blanca-amarillenta (la interior). El aspecto superficial de la piedra, el inusual grosor del revoco exterior que la recubre (superando los 10 centímetros en algunas zonas), y algunas dudas que generaba la estructura de la cubierta, llevan a plantear la posibilidad de que el templo hubiera sufrido un incendio. Se pudo comparar el estado de los sillares de la ermita con otras muestras obtenidas de sillares calcáreos afectados por un incendio, comprobándose que presentan similares características superficiales. Esta hipótesis justificaría una intervención a gran escala (como es el paso de la iglesia-1 a la iglesia-2), la disposición de un potente revoco que ocultara y a la vez reforzara las superficies dañadas por el incendio, y una nueva ejecución de la cubierta, disponiendo su 

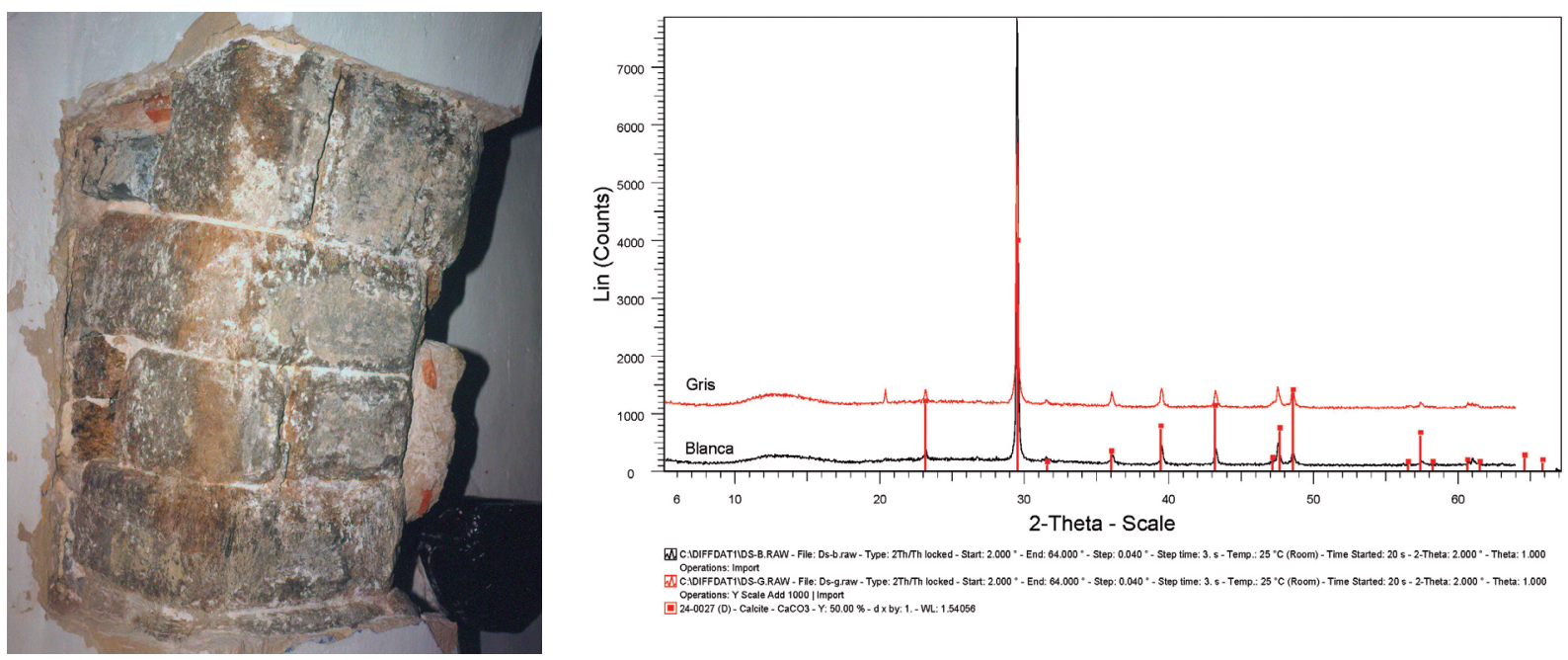

estructura de manera anómala, como veremos más adelante. No obstante, no deja de ser una hipótesis que a día de hoy no se ha podido verificar.

\section{Una tipología representativa}

La siguiente fase del análisis del edificio es el estudio tipológico del mismo. Este estudio nos permitirá comparar la ermita con otros ejemplos similares, que nos aportarán una datación aproximada, y una contextualización de sus elementos y fases constructivas.

La ermita de Santa Margarita de Abejuela representa un claro ejemplo de una tipología que ha recibido varios nombres según los distintos autores: "arte románico terciario" o "iglesias de armadura sobre arco" (Tormo, 1923), "protogótico” o "iglesia valenciana de reconquista” (Garín, 1935), "gótico primitivo" (Guitart Aparicio, 1979), "iglesias de cubierta de madera sobre arcos perpiaños apuntados" (Zaragozá y García Lisón, 1983), “iglesias góticas sobre arcos diafragma” (Benito Martín, 1991), etc. Es abundante la bibliografía al respecto, recogiendo sobre todo estudios realizados en la zona oriental de la Península Ibérica, correspondiente con la antigua Corona de Aragón, localización donde este tipo presenta su mayor densidad. Rechazaremos los términos que incluyan adscripciones a estilos artísticos relacionados con determinada época histórica (románico, gótico, reconquista), ya que, aunque justificados, no resultan representativos para un tipo cuya pervivencia abarca más de cinco siglos. Resulta preferible, por tanto, centrarnos en sus características constructivas, para
De izquierda a derecha y de arriba a abajo:

Figura 12 (página anterior)

Esquema de la toma de muestras para el análisis químico de morteros de junta.

Figura 13

Sillares observables en la cata realizada en uno de los arcos diafragma.

Figura 14

Difractogramas obtenidos tras el análisis por DRX de las muestras de piedra.

Tabla 1. Resultados obtenidos en el análisis químico de morteros de junta.

\begin{tabular}{lcccccc}
\hline Muestra & Calcita & Yeso & $\begin{array}{c}\text { Filosilica- } \\
\text { tos }\end{array}$ & $\begin{array}{c}\text { Fieldes- } \\
\text { pato }\end{array}$ & Cuarzo & $\begin{array}{c}\text { Hidromag- } \\
\text { nesita }\end{array}$ \\
\hline $\mathrm{N}-1 \mathrm{~b}$ & 86 & & 14 & & & \\
\hline $\mathrm{N} 2$ & 62 & & 22 & 14 & 2 & \\
\hline $\mathrm{N} 3$ & 79 & & 18 & & 3 & \\
\hline $\mathrm{N} 4$ & 60 & 16 & - & & & 24 \\
\hline $\mathrm{S} 1$ & 10 & 90 & - & - & \\
\hline $\mathrm{S} 2$ & 77 & & - & 5 & \\
\hline $\mathrm{S} 3$ & 97 & & - & 3 & \\
\hline $\mathrm{Q}-1$ & 92 & 6 & - & 2 & \\
\hline $\mathrm{E}-1$ & 94 & & - & 6 & \\
\hline EA-1 & 4 & 59 & 20 & 17 & \\
\hline $\mathrm{M}-1$ & 96 & & - & 4 & \\
\hline $\mathrm{T}-1$ & 89 & & - & & 11 & \\
\hline
\end{tabular}

( - ) : Componente minoritario / error técnico 2\%-3\% 

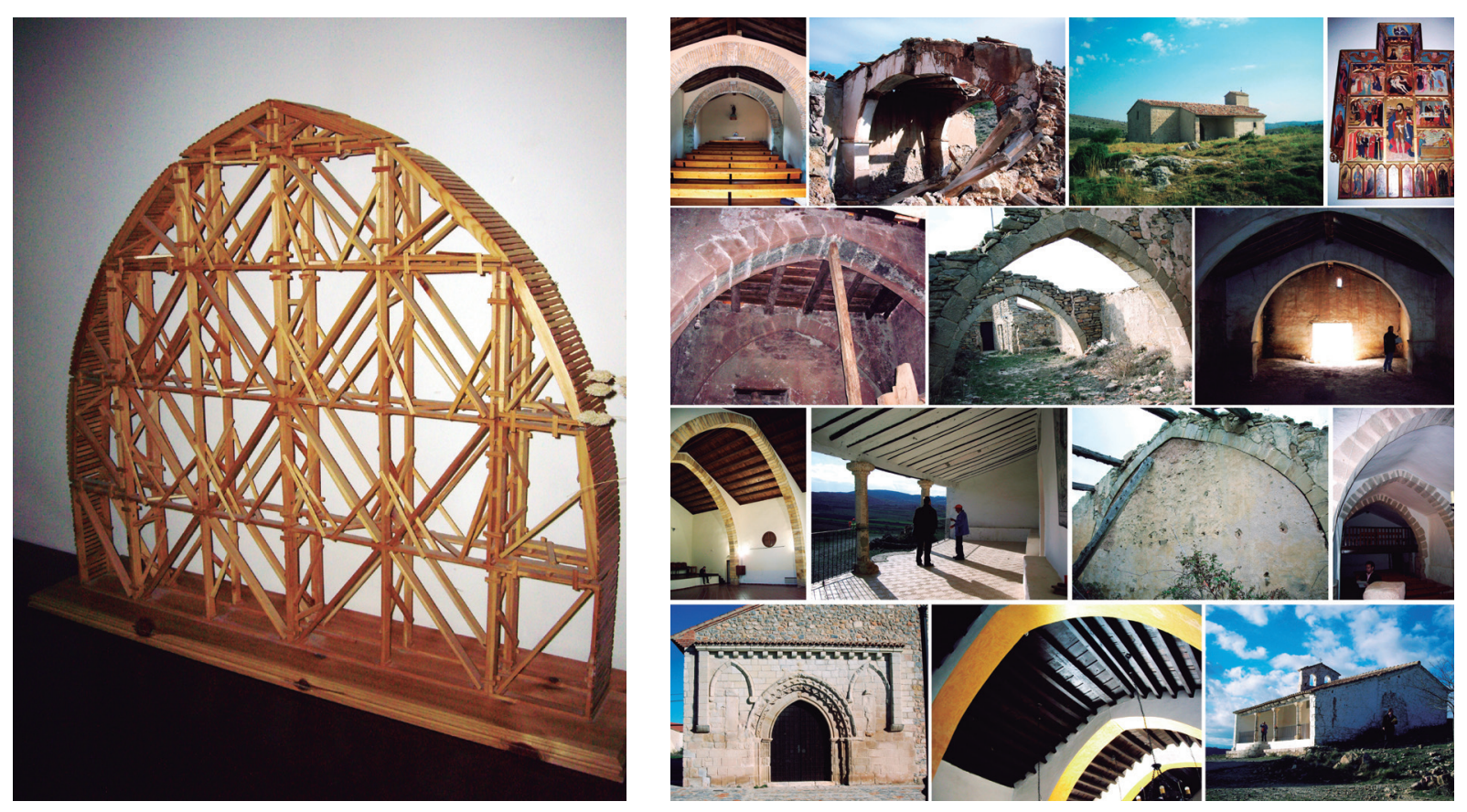

concluir denominando este tipo como "iglesias de arcos diafragma y armadura de madera", recogiendo la denominación que el mismo Zaragozá (2004) redefine; tomando sus palabras, se trata de un tipo "formado por una serie de arcos de fábrica dispuestos transversalmente al eje longitudinal de la nave que se pretende cubrir. Los arcos tienen la función de soportar la cubierta del edificio, en la que la techumbre es de madera" (p. 110). No se hace mención a estilos porque la tipología resultó transversal a la implantación general de varios estilos diferentes; no se hace referencia tampoco a la forma de los arcos, porque podemos encontrar arcos de medio y apuntados indistintamente, incluso rebajados, dentro de la misma tipología. Las referencias históricas de la denominación ("de Reconquista") son justificadas por resultar esta una tipología cuya implantación coincide con el periodo de mayor avance de los reinos cristianos peninsulares sobre los árabes, durante los siglo XIII al XV, pero al mismo tiempo resultan inapropiadas para ejemplos posteriores. Resulta una tipología ampliamente utilizada, cuyo origen encontramos en construcciones de la antigua Roma, y cuyo sistema constructivo ha pervivido en el entorno mediterráneo. Su periodo de esplendor abarca desde el siglo XIII hasta el siglo XV, aunque pervive con modifica- ciones cada vez más acusadas hasta el siglo XVII, y será objeto de reinterpretaciones en clave historicista en los siglos XIX y XX. Es, por tanto, una tipología de amplísimo recorrido histórico. Su principal característica, paradójicamente, pese a mostrar el maderamen de la cubierta visto, es la de ser el sistema constructivo que menor madera necesita, al requerir de solo una cimbra para construir los sucesivos arcos, ahorrando así los costosísimos apeos y cimbras de madera que requiere un sistema abovedado, o las escuadrías y longitudes de piezas necesarias en un sistema atirantado (Figura 15).

Corresponde a esta fase de nuestro análisis la identificación de las características de la ermita de Santa Margarita que permitan englobarla dentro de esta tipología, así como la comparación con otros ejemplos $^{10}$ (Figura 16), para poder ubicar temporalmente sus diferentes fases. En efecto, nuestra ermita reúne casi todos los elementos que se consideran definitorios del tipo:

Nave única, de proporción rectangular.

10. Para la realización de ese estudio comparativo se estudiaron un total de 135 edificios, de los cuales se visitaron in situ 30 , analizando documentalmente el resto a través de publicaciones. 
- Arcos diafragma: en número de tres, apuntados, basados en la forma del triángulo equilátero, llegando hasta el suelo, sin imposta.

- Armadura de madera: aunque solo visible en dos tramos de arcos diafragma (el tercero, el presbiterio, aparece cubierto por las bóvedas vaídas).

- Acceso lateral desde el sur, en el penúltimo tramo desde el presbiterio: en este caso, en el tercer tramo, ya que la iglesia original de arcos diafragma constaba de cuatro tramos.

- Porche previo: protegiendo el acceso, al sur.

- Cabecera plana: actualmente oculta por la primera estancia de la casa de los caridaderos (Figura 17).

Algunos elementos, además, nos permiten aventurar cierta datación del templo original (la iglesia-1) (Zaragoza, 1990). Así, la forma ojival de los arcos nos remite al periodo medieval, ya que los arcos de medio punto en este tipo de iglesias comenzaron a aparecer
De izquierda a derecha y de arriba a abajo:

Figura 15 (página anterior)

Maqueta de la cimbra utilizada para la reconstrucción de uno de los arcos diafragma de la ermita de la Sangre de Cristo en Sarrión, Teruel.

Figura 16 (página anterior)

Algunos ejemplos de ermitas e iglesias de arcos diafragma visitadas por el autor.

Figura 17

Ficha tipo de características realizada para cada ejemplo de ermita visitado.

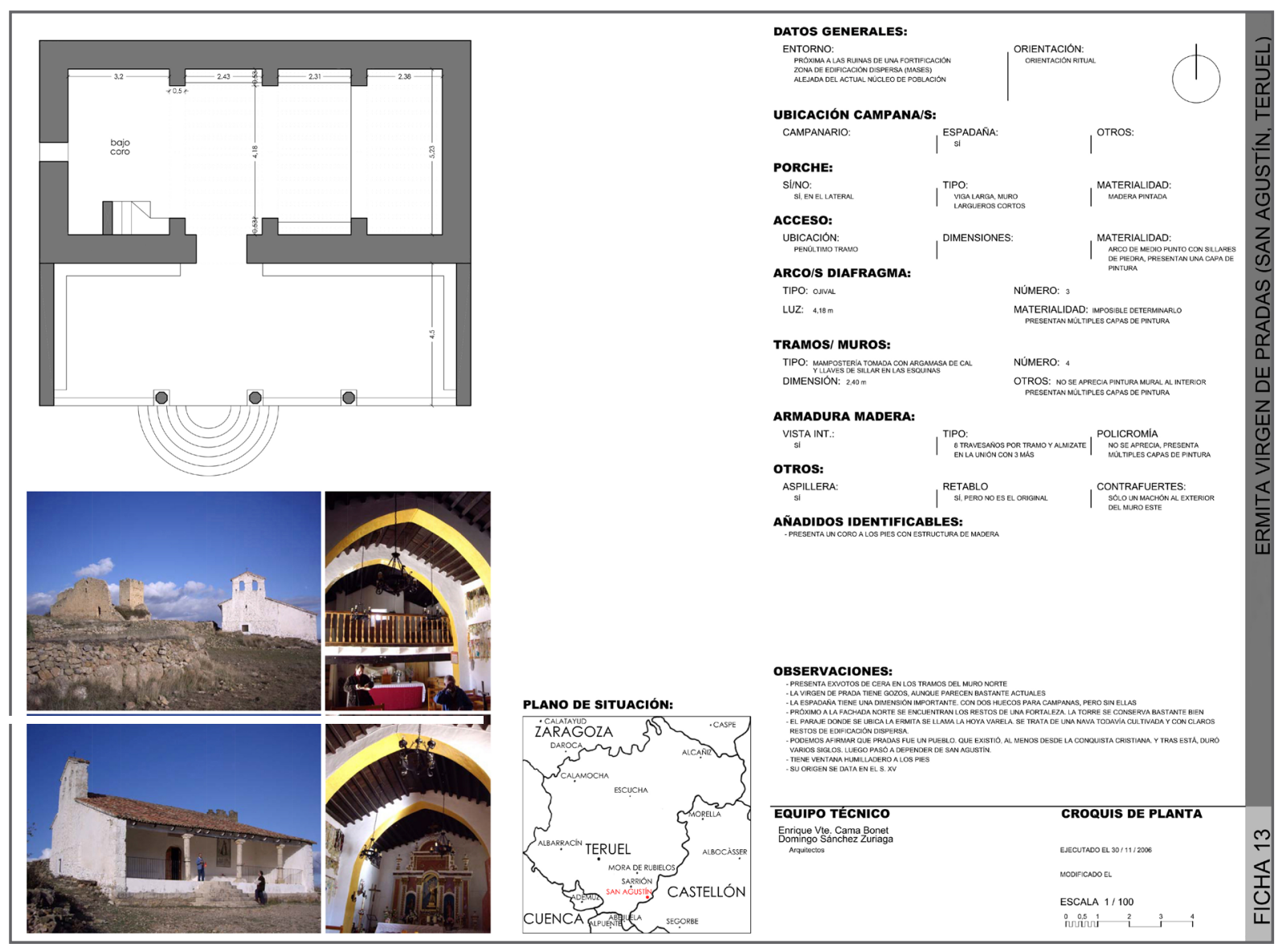


en el siglo XV; del mismo modo, la situación lateral de la puerta, en la penúltima crujía, es también habitual de este periodo, mientras que un acceso centrado en el eje suele suponer dataciones del siglo XV o posteriores. Resulta también habitual en la tipología encontrar una pequeña pila de agua bendita en las inmediaciones del acceso, que suele presentar algo de decoración. En nuestro caso, aunque dañada, aparece adosada al muro sur, a la derecha del acceso, con un diseño de ovas y fileteado superior e inferior que nos remite a modelos de transición románico-gótico, esto es, siglos XIII y XIV (Figura 18). Sin embargo, la disposición de la armadura de cubierta (con tres vigas principales de arco a arco, y viguetas apoyadas sobre ellas en el sentido de las aguas de la cubierta) sigue más bien ejemplos posteriores al siglo $\mathrm{XV}$, ya que lo habitual en ejemplos anteriores es disponer directamente las viguetas de arco a arco, y la estrechez de los tramos de nuestra ermita (apenas dos metros) así lo recomendaría. Aquí cabría retomar la hipótesis del incendio planteada con anterioridad para justificar un cambio del conjunto de la cubierta en fechas posteriores al siglo $\mathrm{XV}$, disponiendo la nueva con un sistema distinto al inicial. Solo la realización de catas en la zona superior de los arcos diafragma, en busca de los mechinales originales de las viguetas, permi-

Figura 18

Pila de agua bendita existente junto al acceso.

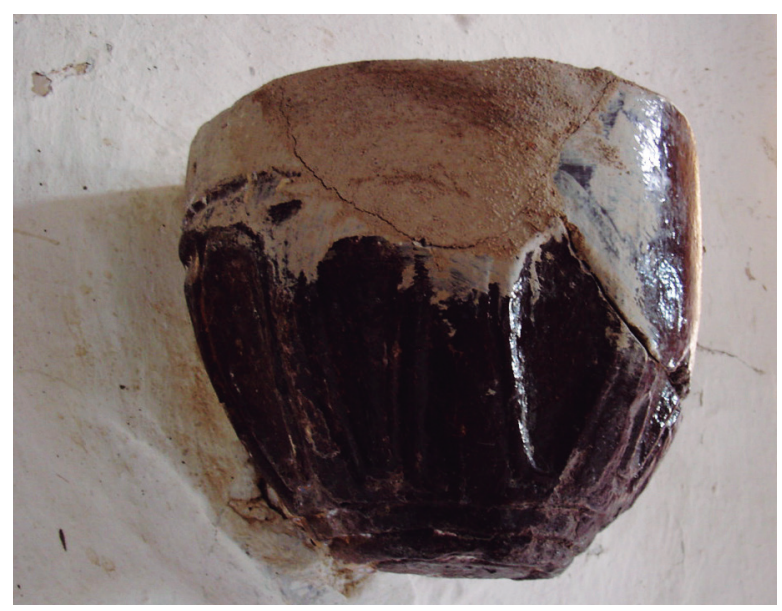

tirían corroborar ese punto. Las proporciones del templo nos permiten englobarlo dentro del grupo de los que fueron (o siguen siendo) parroquias, más que aquellos que se construyeron desde el inicio como ermitas, habitualmente de menores dimensiones, y proporciones más alargadas. La orientación ritual de la nave (con la cabecera orientada hacia el este) es también un síntoma de la antigüedad del edificio, ya que son escasos los ejemplos de iglesias anteriores al siglo XV que no la presenten.

Las adiciones y yuxtaposiciones de elementos también son típicas (Zaragozá, 1990) en una tipología que nace con la intención de permitir su crecimiento (de ahí su uso en estancias conventuales y edificios industriales). Resulta muy habitual la adición de un tramo a los pies para alojar un coro alto, así como de estancias para alojamiento de ermitaños o refugio de pastores. Carece, sin embargo, de adiciones de capillas entre los arcos, por encontrarse estos fusionados con los muros perimetrales, de un grosor considerable para plantearse su perforación. También es frecuente la ocultación de la armadura de madera bajo bóvedas, aunque no tanto la coexistencia de tramos cubiertos y descubiertos, como es nuestro caso.

Resulta extraña la ausencia de un elemento en concreto: un campanario, o espadaña, donde alojar una campana. Es este un elemento habitual, tanto en parroquias como en ermitas, adoptando múltiples formas: la de torre adosada al templo (generalmente de pequeñas dimensiones), la de torre exenta o separada del templo (generalmente relacionada con alguna fortificación o edificio cercano), la espadaña cubierta (con acceso desde el interior del templo por una escalerilla o trampilla) y la espadaña sin cubrir, de uno o múltiples vanos, en posición lateral o central con respecto a la nave. Hasta este punto no hemos observado la presencia de este elemento, ni restos que hayamos podido identificar del mismo. Habrá que esperar a la fase del análisis histórico y documental para encontrar respuesta a esta incógnita.

El análisis tipológico y la comparación con otros edificios similares nos ha permitido la clara adscripción de la ermita a la tipología de iglesias de arcos diafragma y armadura de madera, y dentro de este tipo, datar aproximadamente su fase original (la iglesia-1) en el periodo medieval, entre los siglos XIII y XV. Elementos como el diseño de la pila de agua bendita, y la cercanía de los arcos entre sí (que podría indicar cierta "desconfianza" o falta de desarrollo de un siste- 
ma constructivo poco utilizado todavía) nos podrían situar más bien en el inicio de ese intervalo. Estas conclusiones parciales coinciden hasta ahora con los datos recogidos por el análisis visual, planimétrico y químico.

\section{Estudio histórico: la parroquia de Almansa, la ermita de Abejuela}

Corresponde a esta fase del análisis la obtención de cuantos datos históricos sea posible para contextualizar y datar el edificio y sus fases, así como identificar a sus posibles promotores o constructores. Se debe reseñar en este punto la dificultad de localizar documentación que nos hable tanto del edificio (por sus modestas dimensiones) como de sus usuarios (por encontrarnos en una zona rural, actualmente despoblada, y rodeada de núcleos de población de escasísima entidad, inferiores en su mayoría al centenar de vecinos). A esto hay que sumar el impacto que tuvo en la zona la Guerra Civil Española (desarrollada entre 1936-39, el frente de guerra se sitúo en la zona durante los años 1937 y 1938; las trincheras de uno y otro bando se pueden observar todavía hoy a escasos metros de la ermita) y los sucesos que la precedieron, que supusieron en conjunto la desaparición de muchos archivos (entre ellos, el de la parroquia de Abejuela) y el desmantelamiento de numerosos templos y edificios religiosos (la ermita sufrió el desmantelamiento de su mobiliario y de la cubierta del porche, aunque el edificio también permaneció en pie gracias a utilizarse como hospital).

La referencia histórica más antigua que podemos localizar del templo se encuentra en la toponimia. Ya hemos hablado del topónimo Almansa al referirnos a la nava situada bajo la ermita (la "Hoya de Almansa") y al transcribir una estrofa de los Gozos dedicados a Santa Margarita ("De Almansa nuestros antiguos / se bajaron a Abejuela"). "Almansa" es un topónimo de claro origen árabe: deriva del término al-Mansaf, cuya traducción sería "el lugar que queda a la mitad del camino". No es el único topónimo de tradición árabe que queda en la zona: a escasos kilómetros de la ermita se encuentra la masada de La Almarja, nombre que proviene del término árabe al-mary, "el prado" o "la vega" (y en efecto, es una zona de pastos y agua abundante); también cerca de la ermita encontramos la "Fuente Muza", que toma el nombre propio árabe Musà, equivalente al Moisés hebreo; finalmente, a pocos kilómetros encontramos dos asentamientos con el mismo nombre: Alcotas, que supone la "arabización”, añadiendo el artículo “al”, de la raíz prerromana kott (referida a saliente o pico). La presencia árabe en la zona está más que justificada, y árabe debió ser también, por tanto, el asentamiento de Almansa. El significado del nombre, el "lugar que queda a mitad de camino", podría relacionarse con las rutas de la trashumancia, el transporte estacional del ganado ovino desde los pastos de verano situados en las alturas de las sierras de Albarracín y Javalambre, en Teruel, hasta los pastos de invierno situados en los llanos de Castellón y Valencia, que se realizaba hasta hace unos pocos años. Almansa queda a la mitad exacta de los recorridos trashumantes más habituales, a lo que hay que añadir que las navas suponen una manera muy favorable de avanzar hacia el Sureste evitando los barrancos y desfiladeros de otras zonas. Es bien sabido que la trashumancia fue uno de los motores económicos de la zona, y que se producía incluso cuando el traslado suponía el cruzar desde zonas de dominación cristiana a zonas de dominación árabe. Poco más podemos decir del pasado árabe de Almansa. Solo citar la importancia que tuvo el cercano núcleo de Alpuente en la época, capital de una Taifa o pequeño reino árabe, a la que Almansa debió pertenecer.

La conquista cristiana de la zona corresponde a dos reyes de la Corona de Aragón: Pedro II, llamado "El Católico", y su hijo, Jaime I, llamado "El Conquistador”. Se incorporan a la Corona de Aragón en el reinado de Pedro II las cercanas poblaciones de Mora de Rubielos (1198), Manzanera (1202), Camarena de la Sierra (1213) o la zona del Rincón de Ademuz (1213). No hemos encontrado datos concretos de Almansa, pero cabe suponer que formara parte de este modesto impulso conquistador. Daremos pues como fecha aproximada de la incorporación de Almansa a la Corona de Aragón los primeros años del siglo XIII. No obstante, la frontera se convirtió en una línea difusa y cambiante, como lo demuestra el hecho de que en 1232 se cite Manzanera en poder de los árabes. No será hasta bien entrado el reinado de Jaime I, con Valencia ya conquistada, cuando la frontera deje de ser tal y la zona se apacigüe. El nombre de Almansa aparecerá por primera vez en el reparto de tierras que Jaime I realiza tras la con- 


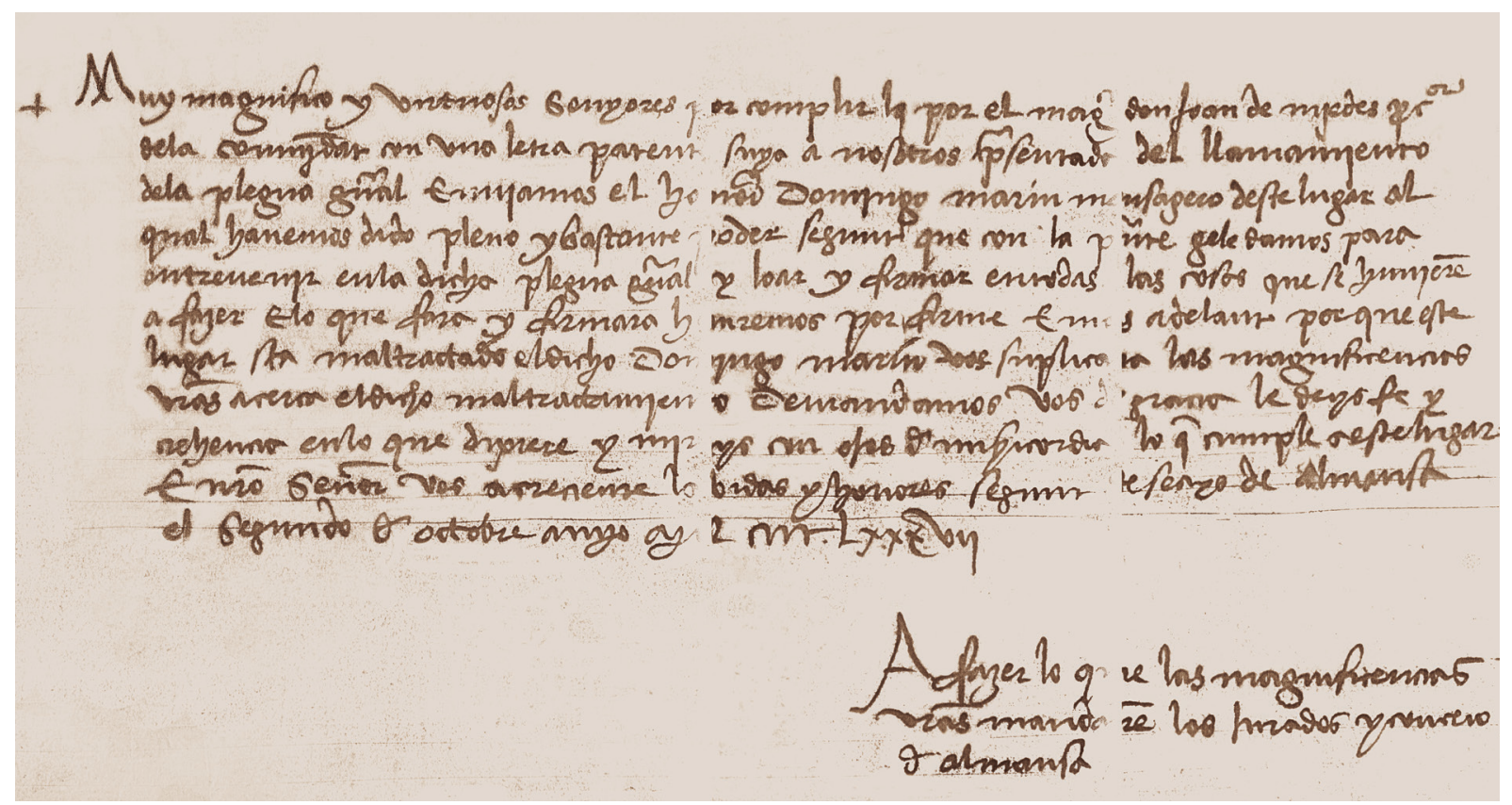

Figura 19

Documento localizado en el Archivo de la Comunidad de Teruel, en Mosqueruela, en el que se cita "almansa".

quista de Valencia, especificando que pertenece a la Comunidad de Aldeas de Teruel y se rige por fuero de esta. No obstante, resulta significativo un documento fechado en Montpellier el 8 de mayo de 1262, en el que el monarca ordena al concejo de Teruel la repoblación de lugares, que hacía tiempo habían sido conquistados, pero que habían quedado despoblados. Entre ellos figuran las actuales poblaciones de Mosqueruela, Camarena de la Sierra y Torrijas, y también se cita a Almansa. Las condiciones de vida en estos lugares, apartados y fríos, los debían convertir en poco apetecibles para el establecimiento de nuevos colonos, con lo que el monarca tuvo que dar un impulso a tal empresa. Desde entonces, podemos localizar el rastro documental de Almansa en algunos documentos, que se conservan en diferentes archivos. ${ }^{11}$ Principalmente se trata de dos tipos

11. Los archivos y bibliotecas visitados para realizar la presente investigación han sido: Archivo Cabré (IPHE, Madrid), Archivo Capitular de la Seo de Zaragoza, Archivo de la Catedral de Valencia, Archivo de la Comunidad de Teruel (IET, Teruel), Archivo de la Diputación de Teruel, Archivo de la Diputación de documentos: de origen civil y eclesiásticos. Será necesario analizar por separado la información recabada de unos y otros:

Documentos civiles: destaca por su antigüedad una orden real de febrero de 1322, de Jaime II, que ordena reparar los mojones que separan Almansa de la vecina Andilla, en el reino de Valencia. La división en reinos (a modo de un "estado federal") de la Corona de Aragón provoca que Almansa siga siendo

$\overline{\text { de Valencia, Archivo de la Diputación Provincial de Zaragoza, }}$ Archivo del Arzobispado de Valencia, Archivo del Arzobispado de Zaragoza, Archivo del Reino de Aragón (Zaragoza), Archivo del Reino de Valencia (Valencia), Archivo Histórico de la Diputación de Teruel, Archivo Histórico Diocesano de Albarracín (Albarracín), Archivo Histórico Diocesano de Segorbe (Segorbe), Archivo Histórico Diocesano del Obispado de Teruel, Archivo Histórico Nacional (Madrid), Archivo Moreno (IPHE, Madrid), Archivo Municipal de Abejuela, Archivo Ruiz Vernacci (IPHE, Madrid), Archivos del Instituto de Patrimonio Histórico Español (Madrid), Arxiu dels Campaners de la Catedral de València, Arxiu Mas (Barcelona), Biblioteca del Instituto de Estudios Turolenses (Teruel), Biblioteca del Instituto de Patrimonio Histórico Español (Madrid), Biblioteca del Museo de Teruel, Biblioteca Nacional de España (Madrid). 
frontera, esta vez entre los reinos de Aragón y de Valencia. La vecindad con la villa de Andilla generará problemas hasta bien entrado el siglo XVIII. También se cita a Almansa en el registro de Monedaje (pago de impuestos) efectuado en 1342, citando que tiene 32 vecinos fiscales (lo cual viene a supone aproximadamente 32 familias efectivas), con apellidos de origen toponímico que relacionan la población con otros núcleos como Alfambra, Aliaga, Formiche, Teruel... El 2 de junio de 1360 está fechado un documento que recoge la compraventa de unas tierras, describiendo la celebración del acuerdo por parte de las autoridades de Almansa: "[...] vecinos de Almansa Aldea de Teruel è de la Compañía de hombres buenos del Conseio de la dita Aldea plegados a Conseio delant de la Iglesia de Sta Margarita del dito Lugar do es acostumbrado a repichs de la Campana segunt la costumbre de el dito Lugar". Este documento aporta numerosos datos: la inclusión de Almansa como Aldea de la Comunidad de Teruel, la advocación de la iglesia en la época (que se mantiene hoy en día), la calificación de la misma como "iglesia" y no como "ermita", la utilización de la misma como lugar de reunión del concejo, y el dato curioso de los repiques de la campana. Un nuevo registro de monedaje o moravedí efectuado entre 1384 y 1387 distingue entre los vecinos que alcanzan ciertas rentas y, por tanto, tienen que pagar el impuesto, y los que no (calificados como nichil), que están exentos. En total, Almansa presenta seis vecinos pagaderos, y un nichil: en poco más de 40 años la población ha descendido más de un 75\%. Durante el siglo XV encontramos abundante documentación relativa a Almansa, en concreto cartas de presentación de los jurados del concejo ante las reuniones o plegas que las distintas aldeas de la Comunidad de Teruel, reunidas en agrupaciones llamadas sesmas, realizaban periódicamente (la mayoría de estos documentos se conservan en el Archivo de la Comunidad de Teruel, en Mosqueruela). En una de estas cartas encontraremos un vecino con un apellido que tendrá relevancia más adelante: Martínez de la Raga. En su conjunto, demuestran que durante esa época la población mantuvo su presencia administrativa. De 1445, procedente del Archivo del Reino de Aragón, en Zaragoza, existe un fragmento de un libro de cuentas perteneciente a Almansa. Sabemos que en esa época la población era Aduana entre los reinos de Aragón y Valencia, y por ella pasaron, en el año 1445, más de 5,000 kg de carbón, declarado a razón de 3 sueldos jaqueses la arroba. Finalmente, en las Cortes de Tarazona, celebradas en el año 1495, se ordena la elaboración del Censo Universal de Aragón: en él, Almansa figura con tan solo tres vecinos fiscales o fuegos. Es el último documento de carácter civil donde encontramos referencias expresas a Almansa como población. Como apéndice, fechado en 1644 encontramos un documento por el cual un particular pone como aval un trozo de tierra que "confronta con el reguero y la pieza de la Rectoría, en la Oja de Almanssa". Este documento tiene la importancia de citar Almansa no ya como una población, sino como una referencia geográfica, y de nombrar la "Rectoría", esto es, el edificio de la actual ermita.

Documentos eclesiásticos: uno de los más importantes por su antigüedad es el censo de las parroquias que pagaron la décima sexenal (impuesto que supone la décima parte de los beneficios de la parroquia, pagaderos en seis años) emanada del II Concilio de Lyon (1274), dedicado a sufragar una nueva Cruzada en Tierra Santa. Este censo se recoge en el Rationes Decimarum Hispaniae, fechado entre 1279-80, y en él aparece citada como parroquia Almansa, dependiente del Arzobispado de Zaragoza; otro impuesto, esta vez una cuarta pagadera al Arzobispado en cinco años, sitúa a Almansa de nuevo como parroquia en el quinquenio 1293-1298, considerando que tiene una extensión de 8,615 ha, aportando 50 fanegas de trigo, 6 de centeno y 8 de ordio (cebada). La documentación de tipo eclesiástico localizada desaparece hasta bien entrado el siglo XVI: en 1563, el Arzobispo de Zaragoza efectúa una visita a Almansa, y ordena que no se coma dentro de la "hermita de Santa Margarita”, como parece ser costumbre, y que se repare su retablo. Es la primera referencia que sitúa al edificio ya no como iglesia sino como ermita, y el único que habla de su retablo, que suponemos bastante anterior a esta fecha ya que necesitaba repararse. Hasta finales del siglo XVIII no volvemos a encontrar referencias a Almansa: figuran en una carta escrita por el rector de Abejuela al Obispo de Teruel, informándole del pleito que en 1732 tuvo lugar con 
el lugar de Andilla por asunto de fronteras entre los reinos de Valencia y Aragón, cuyo primer episodio en 1360 ya hemos comentado. En la descripción que se hace de ese pleito, se cita la despoblación de Almansa: "[...] con la mudanza de la población [de Almansa] (la de la Reserva fue en el año de 1542 [...])”. La fecha validaría el hecho de que 20 años después se la considerara "hermita", como hemos visto anteriormente. No obstante, en la misma carta se nombra la población como "Almansa de los Cavalleros", y se cita un concejo formado por más de 20 de estos caballeros con sus escuderos, incluso afirmando que se trata de Templarios. Como ya hemos visto, la documentación encontrada no respalda esta información, ya que sabemos que apenas 20 años después de la fecha del primer pleito Almansa apenas contaba con una población de siete familias, y ninguno de ellos eran caballeros, $y$ tampoco hemos localizado referencias a la presencia de Templarios $\mathrm{u}$ otras órdenes religiosas en la zona. Por tanto, debemos poner en duda la información relativa a Almansa contenida en esta carta. Otras cartas que encontramos a lo largo del Siglo XIX, escritas por los párrocos de Abejuela al Obispo de Teruel, hablan de las costumbres de la procesión a la ermita (que no distan demasiado de las practicadas hoy día) y de los altercados provocados por el tradicional (y que hoy también se conserva) reparto gratuito de vino, así como la costumbre ("indecente", según el párroco) de comer dentro del templo, bajo el coro (este dato de 1821 supone la primera referencia expresa al mismo); hablan también de conflictos generados por la propiedad de la caseta anexa a la ermita (la "casa de los caridaderos"), de la que parece ser que apropió el Ayuntamiento en contra de la voluntad de la parroquia, a lo que añade una sucinta descripción de la misma y de la figura del ermitaño residente en ella; finalmente, se recogen también datos de la campana o campanico de la ermita, constando que se bendijo uno en el año 1869.

Hasta aquí la documentación, tanto civil como eclesiástica, muestra un núcleo conquistado a los árabes con anterioridad a 1262, fecha en que se ordena su repoblación. Durante el siglo XIV la población desciende fuertemente, hasta que a finales del siglo XV apenas cuenta con tres hogares habitados. En el siglo XVI desaparece la documentación de tipo civil generada en Almansa, y a mediados del siglo XVII ya solo aparece como referencia geográfica, citándose en un dudoso documento del siglo XVIII como fecha de su abandono el año 1542. El edificio de la actual ermita consta como parroquia ya en 1279, y de nuevo en 1293, con la advocación de Santa Margarita recogida por primera vez en 1360, además de constar expresamente en esta fecha que existía una campana y que el edificio se utilizaba como lugar de reunión del concejo. Sin embargo, en 1563 figura ya como ermita, constando que contenía un retablo en mal estado en esa fecha. La primera referencia escrita al coro alto la encontramos en 1821, y a los anexos de la casa de los caridaderos, en 1884.

Nos detendremos en dos datos extraídos de este análisis: entre los documentos relativos a las plegas o reuniones de los Concejos celebradas durante el siglo XV conservados en el Archivo de la Comunidad de Teruel, encontramos en dos documentos pertenecientes a Almansa el sello de placa de su Concejo. Este sello actuaba como firma validadora del mismo, y era similar a un escudo heráldico que representaba al lugar. Los dos sellos conservados de Almansa no son exactamente iguales, aunque comparten el mismo motivo central: una gran torre almenada, con puerta y ventanas, acompañada de un lienzo de muro a cada lado. En uno de los sellos encontramos una rama o palma bajo la torre (Figura 20). Podemos realizar una búsqueda de los restantes sellos conservados (López Rajadel, 1984) que comparten aproximadamente el mismo motivo: torres, acompañadas o no de lienzos de muro, o también lo que se conoce en heráldica como "castillos donjonados", lienzos de muro rematados en sendas torres, con una torre central de mayores proporciones. Corresponden a las localidades de Torrijas, Albentosa, Sarrión, Fuentes de Rubielos, Cedrillas, Gúdar, Ababuj y Campos de Aliaga. En todas estas localidades encontramos fortificaciones conservadas hoy en día (baste citar el castillo de Albentosa, las murallas de Sarrión o la torre de Ababuj), o bien referencias de que existieron en su día. Es más, en la zona encontramos abundantes ejemplos de la relación entre iglesias o ermitas y fortificaciones: quizás el mejor ejemplo sea el cercano caserío de Pradas, cuya ermita (también de arcos diafragma y armadura de madera) se sitúa al lado de un castillo con una singular y esbelta torre-puerta (Figura 21 y 22). En la misma Abejuela encontramos una espectacular casa-torre situada en el centro de la población, que la tradición oral dice que albergó en su día una campana (Figura 23). En Villarroya de los Pinares 


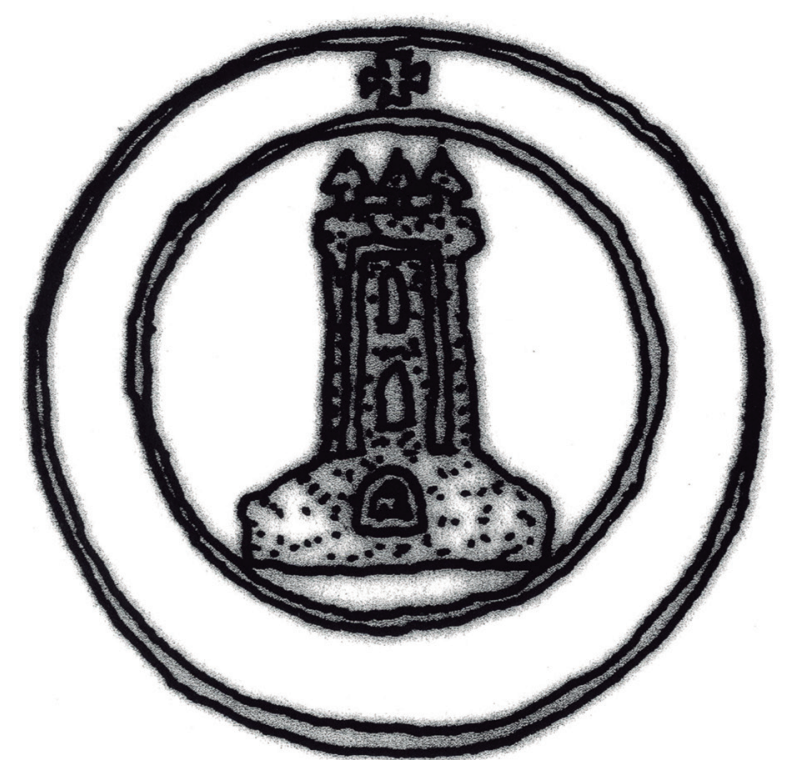

Figura 20

Sellos de placa del Concejo de Almansa en el S.XV.

(cuyo templo era originalmente de arcos diafragma), el imponente torreón conservado en la población se utilizó y utiliza como campanario de la iglesia (a pesar de pertenecer registralmente al Ayuntamiento y no a la parroquia) (Figura 24), como también ocurre en Molinos, mientras que en Camañas el mismo ábside románico de la iglesia (continuada también en arcos diafragma) forma parte de una de las torres del castillo que defendía la población; son todos ellos ejemplos situados en las inmediaciones de la antigua Almansa. ¿Cabe suponer, pues, que Almansa debió contar con una torre defensiva? La fotografía aérea (Figura 25) de la zona muestra los restos, apreciables incluso a nivel de suelo, de una gran edificación a tan solo unos metros de la ermita. Es de planta aproximadamente cuadrada, de unos 10-12 metros de lado. Por los restos conservados, los muros debieron tener un grosor considerable. Desde esta edificación, se puede observar la traza de un muro que la vincula con la ermita. La hipótesis que se plantea desde este estudio es que los restos de esa edificación corresponden a una torre defensiva, que podría haber estado vinculada al edificio de la ermita dotando a este de cierto carácter defensivo. No obstante, es solo una hipótesis que solo una excavación arqueológica de la zona podría corroborar. No resultaría extraño

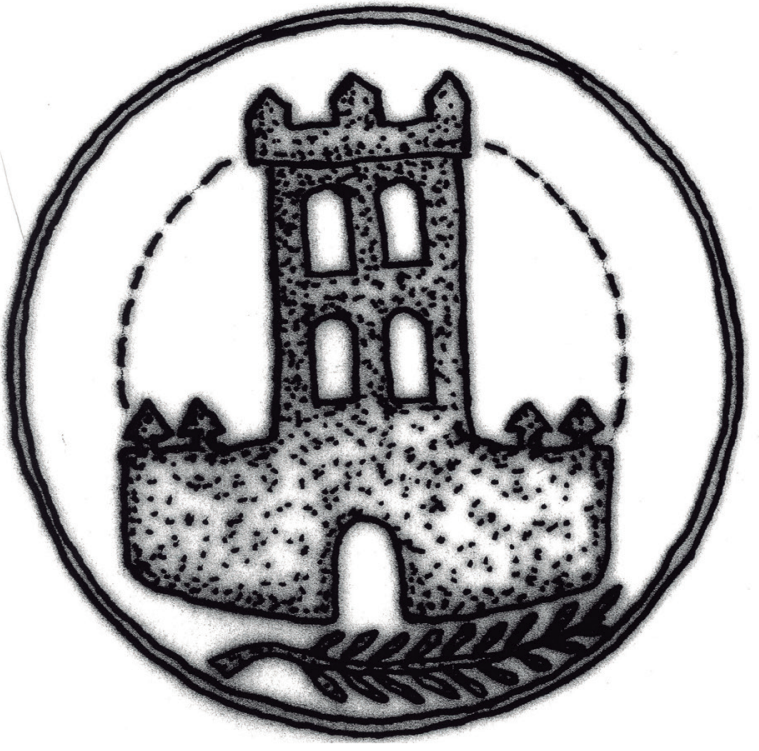

tampoco, como hemos visto en otros ejemplos, que fuera esta torre la que alojara originalmente la campana del templo. No obstante, dado su avanzado estado de ruina, cabe suponer que tras su derrumbe, la campana debió trasladarse a otra ubicación. Pero, ¿dónde? Una fotografía anterior a la Guerra Civil da la clave: la ermita contaba antes de la contienda de 1936 con una pequeña espadaña cubierta, situada en el encuentro entre el porche, la zona del coro, y el testero oeste (Figura 26). El anexo existente en el porche, cuya función hasta ahora no habíamos podido identificar, no es sino la base del acceso a esta pequeña espadaña. Del mismo modo, a ella pertenece el sillar de grandes dimensiones que localizábamos en la fachada oeste. Las incógnitas constructivas del edificio quedan por fin resueltas.

El otro dato en el que profundizaremos es el apellido citado en otra de las cartas de representación de las plegas: Martínez de la Raga. Es un apellido con gran presencia histórica en la zona. Existen casonas pertenecientes a la familia que ostentan su escudo de armas, en las cercanas poblaciones de Abejuela, Alpuente, la masía de Benacatácera, incluso se conserva en el Museo de Bellas Artes de Valencia otro escudo, procedente de su desaparecido palacio en la ciudad. En la iglesia de Abejuela encontramos una inscrip- 

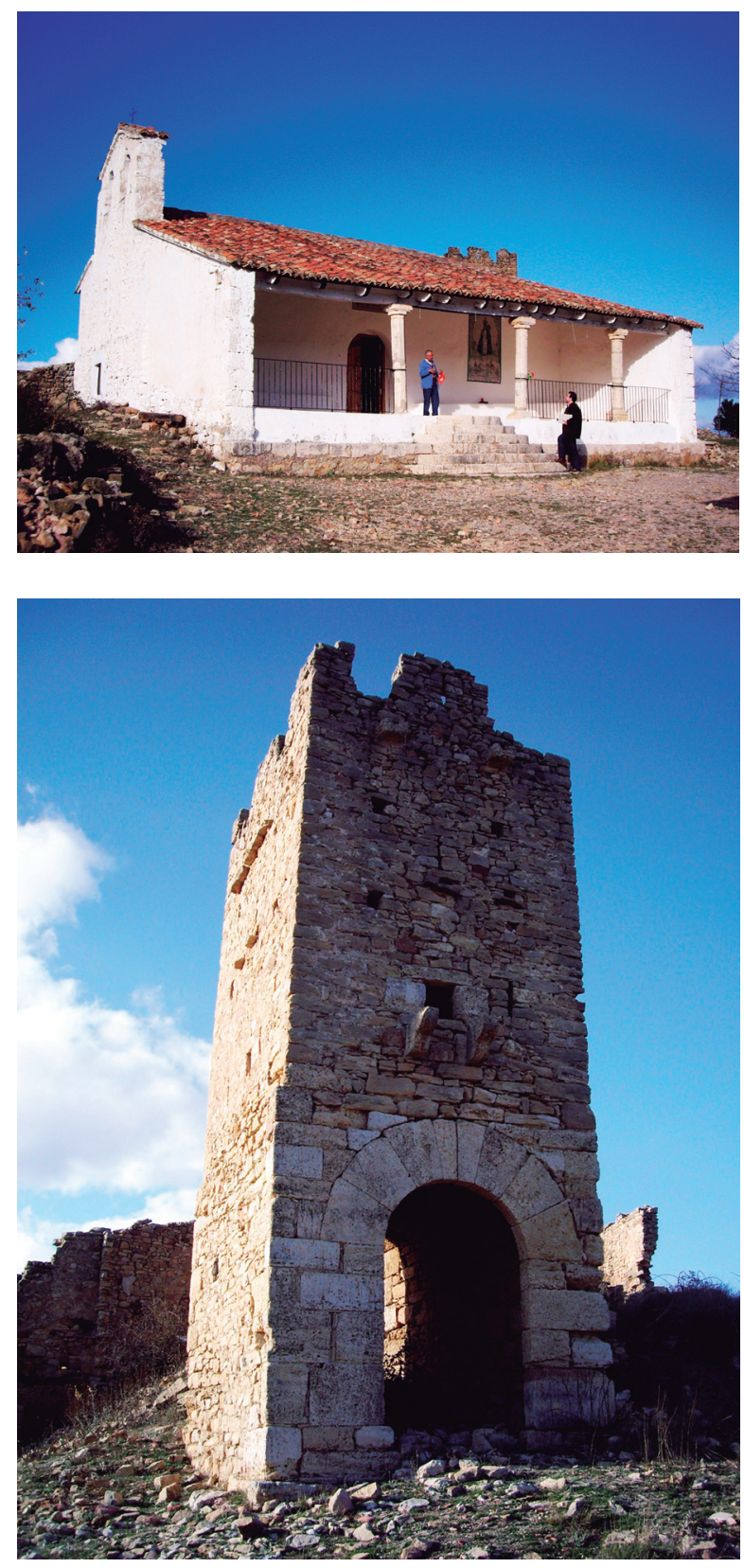

De izquierda a derecha y de arriba a abajo:

Figura 21

Ermita de la Virgen de Pradas, San Agustín.

Figura 22

Castillo de Pradas, San Agustín.

Figura 23 (página siguiente)

Casa-torre ubicada en la Plaza Mayor de Abejuela.

Figura 24 (página siguiente)

Torre de Villarroya de los Pinares. ción $^{12}$ que identifica a dos hermanos, Valero y Ambrosio Martínez de la Raga, naturales de la población, como los promotores y ejecutores de la "renovación" del templo, que supuso una obra de gran envergadura, entre los años 1631 y 1690. Investigando sobre estos personajes encontramos que Ambrosio, como se recoge en la inscripción, fue Secretario y Canciller de la Curia del Arzobispo de Valencia Isidoro Aliaga (O.P. 1565.1648), principalmente recordado por la celebración del Sínodo Diocesano de 1631, del cual se derivan las Advertencias para los edificios y fábricas en los templos: y para diversas cosas de las que en ellos sirven al culto divino y a otros ministerios, un auténtico manual de arquitectura en el cual se explican las características que deben tener los templos católicos para cumplir con las prescripciones del Concilio de Trento. La importancia de esta publicación es enorme en el entorno del levante peninsular, ya que bajo su influjo se produjo un extraordinario impulso constructivo y transformador, que afectó a la mayoría de edificios medievales, que en muchos casos pervivían sin grandes transformaciones, y a otros muchos de nueva planta. La adición de un coro alto a los pies, la necesidad de disponer de una sacristía y de espacios anexos para almacenaje, son ejemplos de algunas de las disposiciones recogidas en las Advertencias. La "renovación" del templo de Abejuela (más bien la demolición del templo original, del que apenas quedan algunos restos en la fachada), curiosamente iniciada el mismo año de la publicación de las Advertencias, bien puede adscribirse a ese impulso. Es habitual, en estas fechas y en numerosas poblaciones del entorno, la aparición de un personaje eclesiástico de importancia, que promueve reformas en los templos de la humilde localidad de la que procede. Así ocurre, por citar dos ejemplos, con Fray Juan Cebrián, general de los Mercedarios, Obispo de Teruel y Arzobispo de Zaragoza (OP 1644-1662), natural de Perales del Alfambra, que transformará totalmente el templo de la localidad y edificará varias ermitas; y con Mons.

12. La transcripción completa de la inscripción es:

EN EL AÑO [IHS, MARIA, IOSEPH] DE 1631 EMPEÇO LA RENOVACION DE ESTE TEMPLO EL DR. AMBROSIO MARTINEZ DE LA RAGA Po. NATURAL DE ESTE LUGAR SECRETARIO I CANCILLER DE LA CURIA DEL EXM ${ }^{\circ}$ SR. ARCOB ${ }^{\circ}$. DE VAa. DESDE 1637 LA PROSIGUIO SU HERMANO VALERO MARTINEZ DE LA RAGA NATURAL DEL MISMO LUGAR FAMILIAR DEL SANTO OPFo. I RESIDENTE EN LA MISMA CIUDAD DE VALENCIA I EN EL AÑO DE 1690 LA CONCLUIO EL DICHO VALERO MARTINEZ DE LA RAGA A QUIEN I A LOS SUIOS EL ILM‥ SR. OB'. DE TERUEL CONC ${ }^{\circ}$. POR PROPIA LA PRESENTE CAPILLA I OTROS HONORES CON PRIVILEGIO DADO EN TERUEL A [ ]DE [ ] SEA TODO PARA MAIOR HONRRA I GLORIA DE DIOS" 
Francisco Peña (1540-1612+), natural de Villarroya de los Pinares, que llegó a ser presidente del Tribunal de la Rota en Roma, y acometió una espectacular reforma del templo de su localidad (en origen, de arcos diafragma) que quedó inacabada. Volviendo a los Martínez de la Raga, y conociendo la devoción existente en Abejuela por la ya por entonces ermita, y las necesidades de intervención en la misma (al menos en su retablo), y teniendo en cuenta la relación de Ambrosio con el Arzobispo impulsor de la transformación de los templos medievales, y su propio afán edificatorio (como se observa en la iglesia de Abejuela), cabe plantear la hipótesis de que fuera él o su hermano Valero el promotor de las reformas de envergadura en la original iglesia-1 de la que procede nuestra ermita, para dar lugar a la iglesia-2, y quizás provocar la inercia suficiente para llegar en poco tiempo hasta la fase de la iglesia-3: las reformas que definen el paso de unas fases a otras (adición del coro alto a los pies, dignificación del presbiterio mediante bóvedas, construcción de la sacristía y de espacios anexos, homogenización de los acabados interiores y de la planta del conjunto, etc) se corresponden con las recogidas en las Advertencias, y el estilo de las mismas se corresponde con un barroco no excesivamente recargado como el de finales del siglo XVII. Fue quizás entonces cuando se ejecutó también un nuevo retablo, al que debió pertenecer un fragmento de cabeza encontrado en las cercanías de la ermita (Figura 27), presumiblemente desmantelado en la Guerra Civil, y que se corresponde estilísticamente con la época. De ser así, podríamos ubicar en el tiempo la principal transformación del templo, el paso de la iglesia-1 a la iglesia-2, aproximadamente en la segunda mitad del siglo XVII. No obstante, esto no deja de ser una hipótesis, que investigaciones posteriores deberán corroborar.

\section{Conclusiones y propuestas de intervención}

La metodología del análisis del patrimonio construido no debe verse determinada por el valor que a priori adscribamos al objeto de estudio. De ser así, el estudio de la ermita de Santa Margarita, un edificio ciertamente modesto, aislado, que no figura en las guías, sin apenas decoración ni elementos significativos, hubiera finalizado mucho antes. Quizás esto provocara que siguiéramos sin entender la función del anexo del porche o los canes de piedra sobre el acceso, desconociéramos la relación del edificio con las construcciones circundantes y con la historia de la zona, o ni siquiera reparáramos en la planta cua-
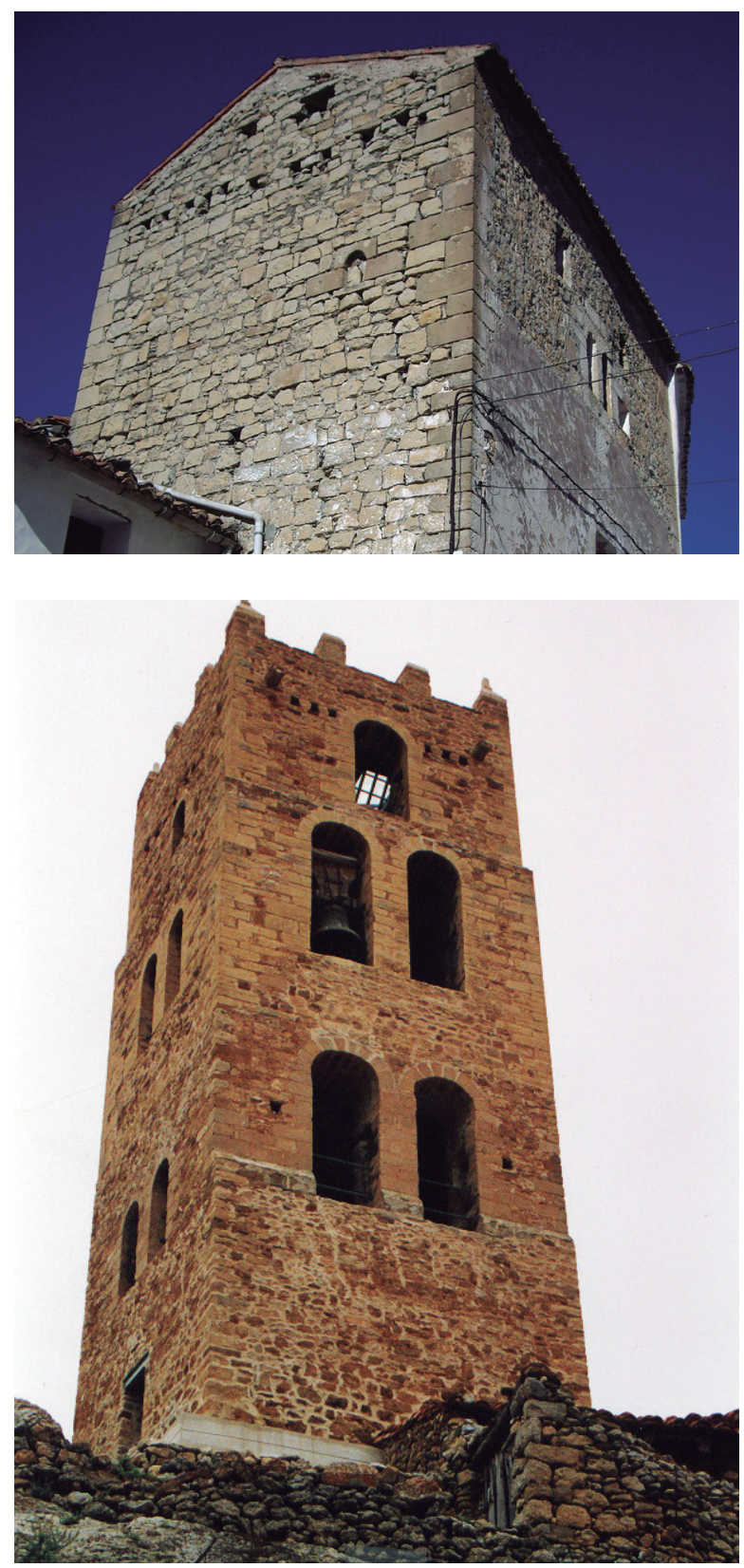


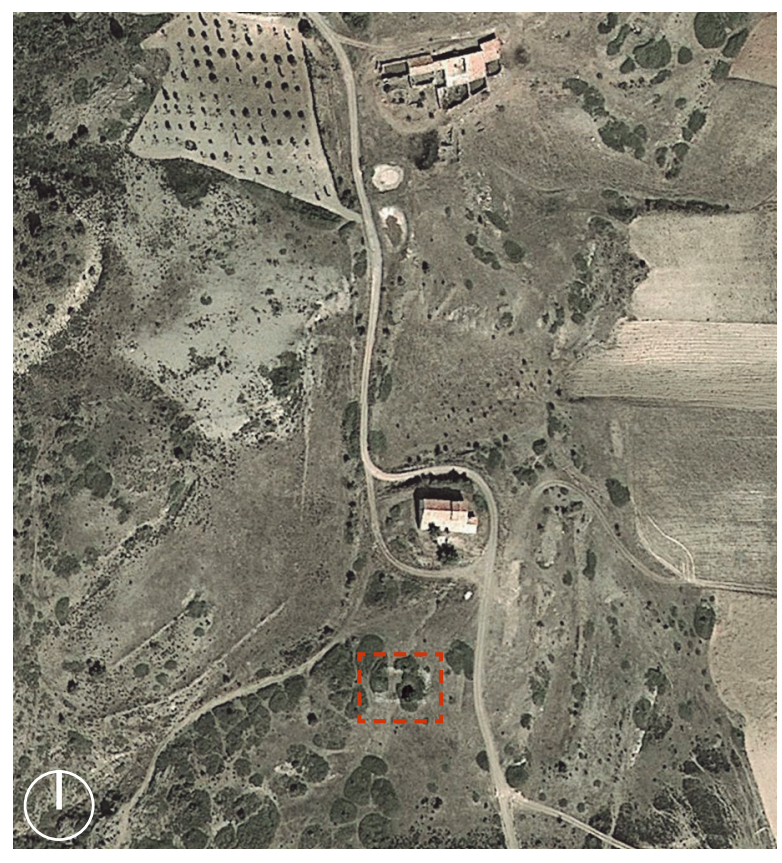

drada que definen unas piedras cercanas. Quizás incluso haríamos como algunos, que se dicen conocedores de la zona, y la llamaríamos "Hoya Mansa" en vez de "Hoya de Almansa", justificándolo por lo llano ("manso") de su orografía... Y es así como, aunque el edificio siguiera en pie, mantenido e incluso mejorado a los ojos de muchos lugareños, gran parte de su patrimonio, en sentido amplio, se iría perdiendo.

Este tipo de análisis es, además, un paso fundamental al plantearse cualquier intervención en el edificio. Y no solo debe entenderse como una fase previa, sino como un proceso permanentemente activo, a la espera de que las obras que se desarrollen ofrezcan nuevos datos a medida que avancen, como muy previsiblemente harán. Serán las conclusiones de este análisis las que nos den las herramientas para tomar las decisiones correctas, que nos permitan poner en valor toda la información que contiene el monumento. Una actuación en la actual ermita debería conocer las fases constructivas del templo y ponerlas en valor, respetando no obstante las intenciones y características particulares de cada etapa. El muro norte, un auténtico "libro de fábrica" del edificio, deberá conservar la legibilidad de sus etapas, lo cual se puede conseguir, por ejemplo, con distintos espesores en el rejuntado de las piezas de sus paños, que diferencien sus fases. Los elementos coetáneos debe-
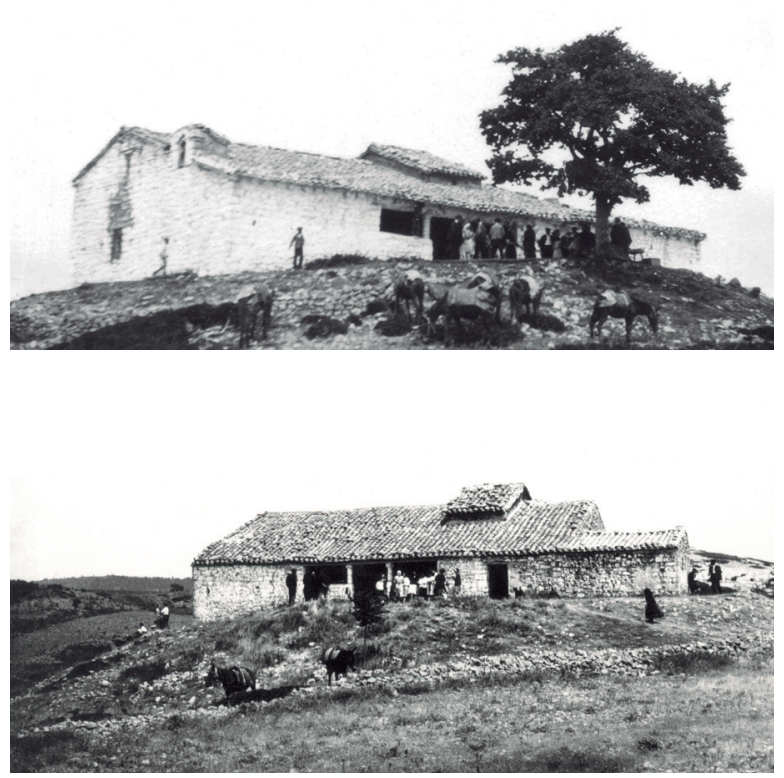

rán presentar un mismo tratamiento para facilitar su comprensión, mostrando no obstante especial cuidado en no generar un todo incoherente o confuso. Elementos en desuso como los canes del porche deberán recuperar su función. En el interior, la voluntad de homogeneizar el conjunto, como ya hemos citado, queda patente, y es una de las características de la intervención que da paso de la fase 1 a las fases 2 y 3: por tanto, deberá mantenerse (buscando el acabado original mediante catas) para no perder las cualidades esenciales y la voluntad original de ese proceso histórico; no obstante, resultará interesante dejar una pequeña zona con los sillares de un arco vistos, a modo de "ventana arqueológica", que no interfiera la visión del conjunto, pero permita "asomarnos" a la construcción original. La cubierta de la zona de los arcos diafragma deberá recuperar su disposición original, en el caso de demostrarse esta. Los espacios anexos deberán adecuarse para mantener su uso residencial (quizás como albergue o refugio para excursionistas), recuperando la entreplanta desaparecida. Finalmente, dado que se conserva la base del elemento y una fotografía que describe perfectamente su forma, debería recuperarse la espadaña cubierta que alojara la campana, dotando así al edificio de todos los elementos que la definen como ermita. En las inmediaciones, sería recomendable 
De izquierda a derecha y de arriba a abajo:

Figura 25 (página anterior)

Fotografía aérea de la ermita y sus inmediaciones.

Fuente: Google Earth (c)2013

Figura 26 (página anterior)

Fotografía de la ermita anterior a 1936.

Fotografía de la ermita inmediatamente posterior a la Guerra Civil Española, donde se puede observar la desaparición de la espadaña y del gran olmo situado junto a la ermita.

Fotografías cedidas por Ma Teresa Llatas.

Figura 27

Fragmento de cabeza en madera encontrado en un campo situado en las inmediaciones de la ermita.

una campaña de excavaciones arqueológicas, que a buen seguro aportaría numerosos datos sobre el poblamiento de la zona, con especial atención a la zona de la supuesta torre.

Como criterio general, todas las actuaciones que se realizaran en la ermita y en su entorno deberían ir dirigidas a poner en valor la legibilidad de las distintas fases y la diacronía de las mismas, pero sin eliminar o enmascarar los elementos que definan la sincronía de cada fase y cada momento histórico, y siempre siguiendo el criterio de la mínima intervención. Al fin y al cabo, el monumento es siempre el que tiene la última palabra, y nuestra labor deberá ser entendida como la de ayudarle a expresarla con toda la amplitud posible, para todo aquel que esté interesado en escucharla.

\section{Agradecimientos}

En primer lugar, a Enrique Vicente Cama Bonet, compañero de estudios, colega de profesión y buen amigo, por ser el 50\% de esta investigación.

En segundo lugar, a todas aquellas personas que formaron parte del equipo técnico multidisciplinar que, de una u otra manera, y siempre desinteresadamente, participó en esta investigación: Pablo Rafael

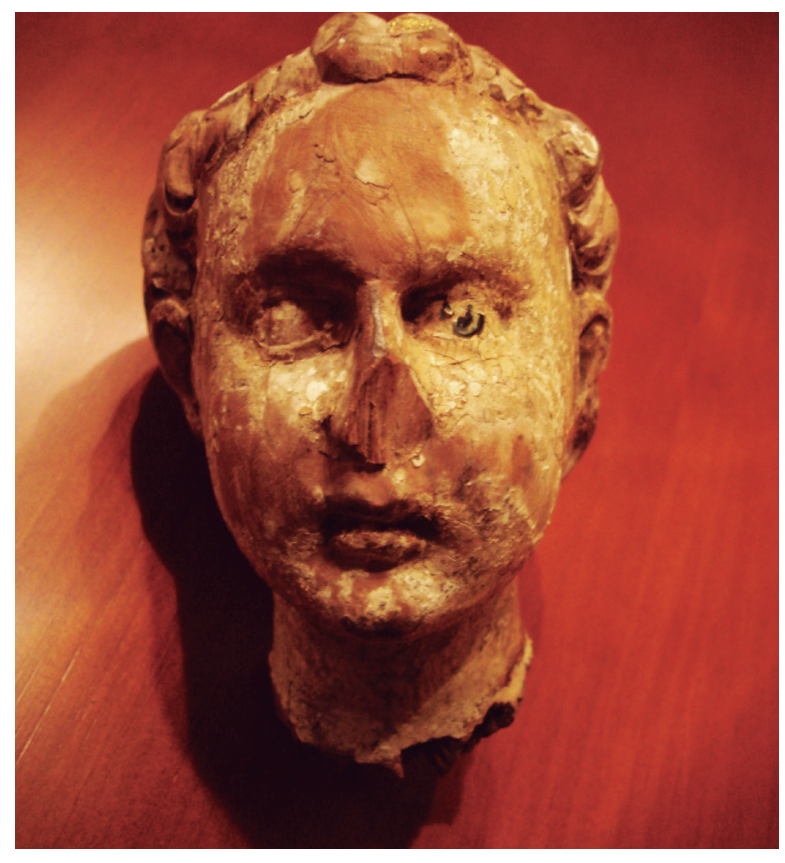

Pardo Ibáñez, del ICMUV (en lo correspondiente a los análisis químicos); Soledad García Sáez, del IRP (en el levantamiento fotogramétrico); Javier Carreras de Bergareche (en la interpretación de la toponimia árabe), y muy especialmente los distintos profesores del MRRP, sin cuya colaboración e implicación el proyecto no hubiera salido adelante: Javier Rivera Blanco, Lauro Olmo Enciso, Carlos Aymat Escalada, Antonio Sánchez-Barriga Fernández, Jose Mª García de Miguel, Jose Luis González Moreno-Navarro... También cabe citar en este punto a los responsables de los archivos que abrieron sus fondos a esta investigación, en especial los del Obispado de Teruel y el Instituto de Estudios Turolenses por su implicación y disponibilidad.

Finalmente, reconocer desde estas líneas la labor de los habitantes de los pueblos visitados, que son los principales actores en la conservación de su patrimonio, y que en la mayoría de las ocasiones se volcaron con esta investigación: los vecinos de Abejuela, La Yesa, El Toro, San Agustín, Camarena de la Sierra, Rubielos de Mora, Fuentes de Rubielos, Caudé... y tantos otros. A ellos dedico todo el esfuerzo realizado, y confío sinceramente en que sobre ellos revierta todo el bien que puedan generar investigaciones de este tipo. 


\section{Bibliografía}

Aguirre González, F. J. (Director) (2005). Catálogo del Archivo de la Comunidad de Teruel (Mosqueruela). Teruel-Zaragoza: Instituto de Estudios Turolenses.

Almagro Basch, M. (1984). Las alteraciones de Teruel, Albarracín y sus comunidades en defensa de sus Fueros durante el siglo XVI. Teruel: Instituto de Estudios Turolenses.

Belenguer, E. y Garín, F. (2006). La Corona de Aragón: el poder y la imagen de la Edad Media a la Edad Moderna (siglos XII-XVIII). Barcelona: Lunwerg, Sociedad Estatal para la Acción Cultural Exterior,

Benito Goerlich, D. (coord.) (1989). La España Gótica. Valencia y Murcia. Madrid: Ediciones Encuentro.

Caruana Gómez de Barreda, J. (1950). Índice de pergaminos, y documentos insertos en ellos, existentes en el Archivo de la ciudad de Teruel. Madrid: Cuerpo Facultativo de Archiveros, Bibliotecarios y Arqueólogos.

Gárate Rojas, I. (2002). Artes de la cal (2 ed.). Madrid: Munilla-Lería.

Gargallo Moya, A. J. (1984). Los orígenes de la comunidad de Teruel. Teruel: Instituto de Estudios Turolenses.

Gargallo Moya, A. J. (1997). El concejo de Teruel en la Edad Media: 1177-1327. Teruel: Instituto de Estudios Turolenses.

Garín Ortiz de Taranco, F. M. (1935). Aspectos de la arquitectura gótica valenciana: ensayo de génesis estilística. Valencia: viuda de Pedro Pascual.

Guitart Aparicio, C. (1979). Arquitectura gótica en Aragón. Zaragoza: Librería General.

Ledesma Rubio, M. L. (1982). Morabedí de Teruel y sus aldeas, 1384-1387. Zaragoza: Anubar.

Ledesma Rubio, M. L. (1991). Cartas de población del reino de Aragón en los siglos medievales. Zaragoza: Institución Fernando el Católico.
López Rajadel, F. (1984). Improntas sigilográficas de los concejos de la Comunidad de Teruel. ROLDE: Revista de Cultura Aragonesa, (26).

Pérez i Moragón, F. y Jarque, F. (1991). Arquitectura gótica valenciana. Valencia: Bancaja.

Pingarron, F. (1995). Las advertencias para los edificios y fábricas de los templos del Sínodo del Arzobispo de Valencia Isidoro Aliaga en 1631. Estudio y transcripción. Valencia: Asociación Cultural “La Seu”.

Rius Serra, J. (1946-47). Rationes Decimarum Hispaniae (1279-80). Barcelona: CSIC.

Sáenz Guallar, F. J. (Director) (2002). Historia ilustrada de la Provincia de Teruel. Teruel: Diario de Teruel.

Sebastián López, S. (1974). Inventario artístico de Teruel y su Provincia. Madrid: Servicio de Publicaciones del Ministerio de Educación y Ciencia.

Sendra Cendra, M. D. (1966). Aranceles aduaneros de la Corona de Aragón: siglo XIII. Valencia: Anubar.

Sinués Ruiz, A. y Ubieto Arteta, A. (1986). El Patrimonio Real en Aragón durante la Edad Media: índice de los documentos consignados en el Liber Patrimonii Regii Aragoniae del Archivo de la Corona de Aragón. Zaragoza: Anubar.

Torres Balbás, L. (1952). Arquitectura gótica. Madrid: Plus Ultra.

Ubieto Arteta, A. (1977). Las sesmas de la Comunidad de Teruel. Revista del Instituto de Estudios Turolenses, (57 y 58).

Ubieto Arteta, A. (1984). Historia de Aragón, los pueblos y los despoblados. Zaragoza: Anubar.

Zaragozá Catalán, A. (1990). Iglesias de Arcos Diafragma y Armadura de Madera en la Arquitectura Medieval Valenciana. Tesis Doctoral, Universidad Politécnica de Valencia.

Zaragozá Catalán, A. (2004). Arquitectura gótica valenciana: siglos XIII-XV. Valencia: Generalitat Valenciana, Conselleria de Cultura, Educación y Deporte. 